\title{
LA FRACTURA MEXICANA Y EL GOLPE DE 1954 EN GUATEMALA
}

\author{
Soledad Loaeza* \\ El Colegio de México
}

\begin{abstract}
$\mathrm{F}^{\mathrm{n}}$ junio de 1954 la Central Intelligence Agency (CIA) Eapoyó un golpe militar contra el presidente de Guatemala, Jacobo Árbenz, en una operación similar a la que había llevado a cabo el año anterior contra el presidente Mossadegh en Irán. ${ }^{1}$ En ambos casos, el gobierno de Estados Unidos
\end{abstract}

Fecha de recepción: 24 de abril de 2015

Fecha de aceptación: 27 de octubre de 2015

*Una primera versión en inglés de este artículo fue publicada como Soledad Loaeza, "The Mexican political fracture and the 1954 coup in Guatemala (The beginnings of the Cold War in Latin America)", en Culture E History Digital Journal, 4 (2015). Agradezco a Ana Covarrubias, Susan Eckstein, Graciela Márquez y Ariel Rodríguez Kuri sus comentarios y atinadas observaciones a versiones anteriores. Daniel Cortés recopiló parte de la información.

${ }^{1}$ La intervención de Estados Unidos en Guatemala es un hecho histórico establecido, un "momento reprobable" de la administración Eisenhower. En 1999, durante una visita oficial a ese país, el presidente Bill Clinton dijo: "Estados Unidos hizo mal en apoyar a fuerzas militares y unidades de inteligencia comprometidas en actos de violencia y en represión generalizada, y no debe repetir ese error". Citado en BARRETT, "Sterilizing a 'Red Infection". 
actuó convencido de que combatía la influencia de la Unión Soviética. Para América Latina el episodio guatemalteco fue la señal de que la política del buen vecino había llegado a su fin y la Guerra Fría a la región, donde se instaló como el epicentro de la inestabilidad y los conflictos que sufrieron estos países en la segunda mitad del siglo xx. Como afirma Stephen G. Rabe: "Guatemala fue el terreno de entrenamiento de subsecuentes intervenciones de Estados Unidos en países como Cuba, Brasil, Guyana Británica y Chile”. ${ }^{2}$

La ofensiva de Washington contra un gobierno constitucional, democráticamente elegido, desató una ola de protestas, agrió las relaciones interamericanas y le imprimió un ominoso significado a la noción esfera de influencia. Las denuncias contra Estados Unidos se disolvieron poco después de la caída de Árbenz, pero la huella del golpe quedó impresa en la memoria de los latinoamericanos como testimonio de su vulnerabilidad. ${ }^{3}$

En México los acontecimientos guatemaltecos tuvieron un impacto considerable que ha sido poco estudiado, ${ }^{4}$ pese a que fueron el catalizador de la reorganización de la izquierda que a

2 Rabe, The Killing Zone, p. 53.

3 Rabe, The Killing Zone, pp. 53-58. Blanton, "Recovering the memory of the Cold War”, pp. 47-73, pp. 54-56.

4 Las investigaciones al respecto son escasas. Se han publicado sobre todo referencias apresuradas dentro del tema más amplio de las relaciones Estados Unidos-América Latina, o se cita el caso como ejemplo de la independencia de la política exterior mexicana. Tratan en particular el impacto del golpe en México: Buchenau, "Por una guerra fría más templada”, pp. 119-149; Pellicer, "México en la oeA”, pp. 288-302. Nancy Robinson, “México frente a la crisis de Guatemala en 1954". Los efectos del golpe sobre terceros países son analizados en Hove, “The Árbenz factor”, pp. 623-663; Ferreira, “El caso de Guatemala”, pp. 25-58. 
partir de 1959 se movilizó para apoyar la victoria de los revolucionarios cubanos. ${ }^{5}$ La crisis guatemalteca fue un episodio de la Guerra Fría que acentuó los ecos locales de la rivalidad entre Estados Unidos y la Unión Soviética e instigó la reaparición de la fractura política que había provocado el gobierno radical del presidente Lázaro Cárdenas (1934-1940) en el seno de las clases medias y de la elite política, y que permanecía latente. La reactivación de la izquierda tuvo un efecto divisivo que evidenció la fragilidad de la unidad nacional y puso al descubierto la precaria estabilidad de los equilibrios políticos internos. También sembró la inquietud de que el régimen revolucionario mexicano había caído en la autocomplacencia. Esta convicción inspiró las movilizaciones de los años sesenta.

El expresidente Cárdenas asumió de inmediato el liderazgo del repudio al intervencionismo estadounidense en Guatemala, al frente de diferentes organizaciones de izquierda, incluida una corriente del PRI. Esta actitud y el apoyo solidario a los arbencistas contrastaba con la tibia reacción del presidente Adolfo Ruiz Cortines (1952-1958) y con la hostilidad de una amplia ala francamente anticomunista del personal político y administrativo.

Sin embargo, el discurso autodeterminista de la política exterior mexicana ante los acontecimientos en Guatemala,

${ }^{5}$ El tema ha sido ampliamente tratado y la bibliografía al respecto es voluminosa. Aquí se mencionan apenas unas cuantas obras. Los trabajos pioneros de Pellicer, "La revolución cubana en México”, pp. 360-383; Pellicer, México y la revolución cubana; véase también Fenn, "México, la No-Intervención”, pp. 1-19; las investigaciones más recientes profundizan algunos aspectos de los planteamientos de Pellicer, pero no los modifican de manera esencial, Covarrubias, México y la Revolución Cubana, pp. 25-46; KeLler, "A foreign policy for domestic consumption”, pp. 100-119. 
disimuló estas diferencias. En la X Conferencia Interamericana que se celebró en Caracas en marzo de 1954 para tratar el tema de la influencia comunista en el gobierno guatemalteco, México pudo sostener las apariencias de una política exterior autónoma que le habían ganado crédito internacional en los años anteriores. Los representantes mexicanos resistieron las presiones del secretario de Estado, John Foster Dulles y se abstuvieron de votar la resolución anticomunista que él proponía. Esta decisión requiere una explicación porque el discurso diplomático mexicano reiteraba el compromiso con la defensa de la autodeterminación; pero la tolerancia ideológica que desplegaba México en los foros multilaterales, se desvanecía en el ámbito interno con las medidas policíacas que se aplicaban a los comunistas, tal y como Washington lo esperaba. ¿Cuáles eran los motivos de Ruiz Cortines para actuar en forma tan inconsistente? ¿Cómo vinculaba una política interna y una política exterior radicalmente opuestas?

La investigación académica sobre la política exterior mexicana de la segunda mitad del siglo xx se basa en dos presupuestos generales: primero, que la política exterior es una fuente de consenso nacional, cuyos objetivos se plasman en la defensa de los principios de no intervención y autodeterminación. ${ }^{6}$ Segundo, que entre Estados Unidos y México

${ }^{6}$ Por ejemplo, Mario Ojeda, uno de los principales y más influyentes autores de estudios sobre el tema, afirma: "Es importante dejar señalado el hecho evidente de que en términos generales en México ha existido un consenso relativamente amplio en cuanto a política exterior se refiere $[\ldots]$ ha contado con la aprobación tácita de una mayoría de la opinión nacional". OJedA, Alcances y límites, p. 105. Véase también MeYer, México y el mundo, t. VI. 
existe una relación especial, que consiste en "un acuerdo para discrepar"7 en temas de política internacional, siempre y cuando no estén en juego sus respectivos intereses estratégicos. Este acuerdo sería la base de la relativa autonomía de la política exterior mexicana que ha sido vista históricamente como prueba de esa supuesta relación especial.

La crisis guatemalteca desmiente ambos presupuestos. Primero, la opinión pública mexicana no apoyaba en forma unánime la causa arbencista, incluso en el interior del gobierno había diferencias, entre otras razones porque ponía en riesgo la relación con Estados Unidos y, segundo, en los momentos finales de la crisis guatemalteca, el presidente Ruiz Cortines cooperó con Washington en la lucha por extirpar la influencia comunista del hemisferio y adoptó las medidas que le habían sido solicitadas con ese fin.

La idea de que la política exterior es fuente de consenso interno es difícil de sostener. Primero, implica que la estabilidad interna depende de esa política y, segundo, sobrestima el significado que este tema tiene para la opinión pública o, en todo caso, subestima los desacuerdos que puede provocar. Por ejemplo, el apoyo a la República Española en 1936, la declaración de guerra a las potencias del Eje en 1942 y la alianza de la posguerra con Estados Unidos, dividieron

7 Mario Ojeda cita a un consultor de la Comisión de Relaciones Exteriores del Senado de Estados Unidos, Pat Holt, quien en 1967 sostuvo que México tenía una "dispensa especial para disentir". A partir de ahí, Ojeda elabora lo que se ha conocido en la academia mexicana como el "corolario Ojeda": "Estados Unidos reconoce y acepta la necesidad de México a disentir de la política norteamericana en todo aquello que resulte fundamental a México. A cambio de ello, México brinda su cooperación en todo aquello que siendo fundamental o aun importante para los Estados Unidos no lo es para el país”. OJEDA, Alcances y límites, p. 93. 
en forma tajante a la opinión pública. ${ }^{8}$ Sin embargo, estas diferencias no pusieron en entredicho los equilibrios internos. Por otra parte, más que un entendimiento o un acuerdo de largo plazo para estar en desacuerdo, la relación entre México y Estados Unidos estaba construida con base en negociaciones de corto plazo, sujetas a cambios en las circunstancias inmediatas. Por ejemplo, Ruiz Cortines tuvo un espacio de maniobra más estrecho que su sucesor, Adolfo López Mateos, simplemente porque sus interlocutores en Washington, el presidente Eisenhower y su secretario de Estado, John Foster Dulles, eran más intransigentes y suspicaces que John F. Kennedy y Dean Rusk.

La política de Ruiz Cortines ha sido severamente juzgada. Jürgen Buchenau la describe como un "abandono de los principios revolucionarios" que sólo alcanzó un "frágil equilibrio", ${ }^{9}$ en tanto que Nancy Robinson atribuye la "tibieza" del apoyo al clima conservador del país y a las relaciones "históricamente conflictivas" entre México y Guatemala. ${ }^{10}$ Ambos autores sostienen, acertadamente, que la posición del presidente Ruiz Cortines fue producto de presiones de Estados Unidos y del sector privado mexicano. Sin embargo, Buchenau y Robinson pasan por alto la fractura en el seno de

${ }^{8}$ Véase por ejemplo, Sola Ayape, "Contra las cortes de ultratumba”, pp. 273-304. Manuel Gómez Morín, líder del partido conservador, fundado en 1939, Partido Acción Nacional (PAN), representaba a un amplio sector de opinión que consideraba que intervenir en la guerra era un error y que a México le convenía la neutralidad. AMGM, ITAM, exp. 163, f. PAN, sec. A.N., sub. Organización.

9 Buchenau, "Por una guerra fría más templada", pp. 119-120.

10 Nancy Robinson, "México frente a la crisis de Guatemala en 1954" [en línea] http//www. raco.cat/index.php/boletinamericanista/article/ viewFile/98476/146.119". 
la elite política mexicana que restringía las decisiones presidenciales. Como se verá más adelante, la oposición entre cardenistas y anticardenistas, es central en esta historia. También se verá que la política exterior estaba condicionada por la relación con Estados Unidos y por la política interna, y no a la inversa, como lo plantea el segundo presupuesto de Ojeda.

La falla central de la estrategia de Ruiz Cortines estriba en que diseñó su política exterior en los términos que utilizaba para orientar su política interna. Ariel Rodríguez Kuri sostiene que la presidencia de Adolfo Ruiz Cortines representa el cenit del autoritarismo mexicano, encabezado por un presidencialismo en apariencia omnipotente, que se asentaba en un firme consenso fundado en el crecimiento económico y en la estabilidad política. ${ }^{11}$ Este momento irrepetible del presidencialismo fue producto, nos dice, de la habilidad de Ruiz Cortines para conjurar con pactos y compromisos, las amenazas de caciques regionales, disidentes de la elite política y corporaciones obreras y campesinas. No obstante, fracasó cuando aplicó la misma estrategia a problemas internacionales y cedió un poco a las demandas de cada uno de sus interlocutores. El presidente respondía a las demandas de los cardenistas con un discurso público que defendía la autodeterminación, pero en privado atendía al embajador de Estados Unidos y atacaba al comunismo, y tomaba medidas persecutorias contra los comunistas. En un principio, el presidente trató de mantener una relación distante aunque cordial con Estados Unidos, que atravesaba por uno de los momentos álgidos de su rivalidad con la Unión Soviética, pero las circunstancias lo condujeron a una estrecha colaboración con la cruzada de la

11 Rodríguez Kuri, “Los años maravillosos”, pp. 265-286. 
superpotencia. Ruiz Cortines adoptó un doble discurso para reconciliar lo irreconciliable, no disolvió los antagonismos, los mantuvo en equilibrio. Sin embargo, a diferencia de las condiciones de política interna, en el contexto de la Guerra Fría, su política exterior no tenía mucho margen de maniobra pues solo contaba con un interlocutor, Estados Unidos.

La ambivalencia de Ruiz Cortines ante la ofensiva contra la "primavera guatemalteca", como llamaban los arbencistas a sus reformas, era primeramente una reacción defensiva. La prioridad del presidente mexicano era evitar un conflicto con la superpotencia vecina, y preservar el status quo interno que había ganado la aceptación internacional. Temía que si no frenaba las protestas contra Estados Unidos, podían desembocar en una movilización más grande y compleja que provocara una confrontación con el poderoso vecino. A éste lo único que le interesaba era que el orden político en México fuera estable, y que el gobierno respetara su compromiso con el combate anticomunista. En ambos casos el presidente Ruiz Cortines corría el riesgo de que Washington creyera que debía intervenir en México para restaurar una estabilidad que era central para su seguridad.

Las aprehensiones de Ruiz Cortines no eran injustificadas. El intervencionismo era un componente central de la política de Guerra Fría de Estados Unidos. El episodio guatemalteco confirmó, según la observación de un funcionario del Departamento de Estado, que los latinoamericanos tenían más miedo al intervencionismo de Estados Unidos que al comunismo guatemalteco. ${ }^{12}$

\footnotetext{
12 Louis Halle al término de la X Conferencia Interamericana en Caracas, Venezuela. Citado en Rabe, Eisenhower and Latin America, p. 53.
} 
En este artículo reconstruyo la atmósfera crispada que generaba la Guerra Fría en la política interna mexicana, en particular la consolidación en el poder de la coalición conservadora. En la segunda parte, examino la división en el seno de la elite política y las tensiones que el problema guatemalteco acarreó en el resto de la sociedad. Luego discuto la relación de México con Estados Unidos, en el marco más amplio de la estrategia del roll back en América Latina. En esta sección también describo los rasgos específicos del gobierno de Adolfo Ruiz Cortines y las medidas que adoptó para enfrentar las repercusiones de la crisis; y por último, la política de México ante la agresión del gobierno de Washington contra el presidente Árbenz, y sus secuelas en el ámbito interno mexicano.

\section{LA GUERRA FRÍA EN MÉXICO}

La transformación de Estados Unidos en una superpotencia fue el cambio de la posguerra que mayores consecuencias tuvo para México. Desde la derrota de 1847, este país estuvo sujeto a las presiones de un vecino inmediato más poderoso; pero las asimetrías que antes eran significativas, 100 años después, en 1946, eran incomparables. Sólo en términos de población, México tenía 23000000 de habitantes, Estados Unidos 145 y era la primera potencia industrial, económica y militar del mundo. Su tamaño, la proximidad geográfica y su poderío bélico hacían de ese país una amenaza para un vecino que tenía un ejército de 50000 efectivos, y una economía predominantemente agrícola. El gobierno mexicano tenía que estar en permanente estado de alerta a la propensión estadounidense a interferir en los asuntos internos de terceros. 
Nada más que por la geografía, México no podía escapar a la distribución bipolar del poder internacional que acentuó la vulnerabilidad del país a presiones y acontecimientos del exterior. El condicionamiento que le imponía un contexto externo de agudas tensiones favoreció el afianzamiento del régimen autoritario en un periodo de acelerado cambio social. El antagonismo internacional entre la democracia liberal y el comunismo se yuxtapuso a divisiones políticas existentes, en particular a la fractura que oponía a cardenistas y anticardenistas. La Guerra Fría también era el marco de referencia general para la interpretación de la política, en el que se situaban todos los actores, desde la Iglesia católica hasta el minúsculo partido comunista, pasando por la prensa escrita y las diversas corrientes en el interior del PRI.

\section{La coalición conservadora}

Durante los primeros años de la Guerra Fría, una atmósfera de profundo conservadurismo se instaló en México, inducida por la situación internacional y por la presencia en el poder de una coalición conservadora integrada por fervorosos anticomunistas miembros de la elite política y del ejército, grupos de clase media en ascenso, empresarios, católicos de todas las clases sociales, y encabezada por el propio presidente Ruiz Cortines. El reflejo más articulado de esta congregación miscelánea era la doctrina nacionalista del gobierno que buscaba la justificación política y moral de sus decisiones, pero también se proponía otros objetivos, por ejemplo, generar una identidad política homogénea y particular que contribuyera a la despolitización de la sociedad; contrarrestar los efectos desestabilizadores de la 
oposición comunismo-capitalismo, izquierda-derecha en el orden interno, y ofrecer un contrapeso a la influencia cultural de Estados Unidos. La doctrina nacionalista también fomentaba el temor al comunismo. ${ }^{13}$ No obstante, su alcance estaba limitado por los antagonismos ideológicos y las diferencias regionales y sociales que dividían a los mexicanos. Estas divisiones ponían en duda el consenso nacional que supuestamente se había alcanzado durante la guerra.

La fragilidad del acuerdo nacional también tenía causas inmediatas. En primer lugar, en la conflictiva elección presidencial de 1952 participó el general Miguel Henriquez Guzmán como candidato de un cardenismo sin Cárdenas; su derrota nunca fue aceptada por él ni por sus simpatizantes que guardaron un amargo resentimiento. Luego, los primeros tres años del gobierno ruizcortinista fueron difíciles, la economía perdió dinamismo y el crecimiento demográfico ganaba momentum; mientras que la inflación provocaba inquietud entre los trabajadores. Por último, los remanentes de la coalición radical que había formado el cardenismo contenían su descontento en una sorda oposición que no encontraba un canal de expresión apropiado.

El impacto de la Guerra Fría sobre la política interna se manifestó en diferentes ámbitos y de distintas maneras; por ejemplo, en el realineamiento de los actores políticos. En el marco de la alianza con Estados Unidos el combate al comunismo socavó la influencia del ala izquierda de la elite en el poder. Desde 1944 el gobierno, primero Ávila Camacho y Alemán después, relegó a la coalición cardenista y a la corriente del PRI asociada a Vicente Lombardo Toledano,

13 Véase Servín, “Propaganda y Guerra Fría”, pp. 9-39. 
el fundador de la Confederación de Trabajadores de México (Стм), y líder de la Confederación de Trabajadores de América Latina (CTAL). Cardenistas y lombardistas fueron desplazados por una nueva generación de políticos, "los universitarios" - a la que, por cierto, no pertenecía Ruiz Cortines. Este grupo, formado durante los gobiernos de Ávila Camacho y de Alemán, fue el eje de la coalición que alcanzó el poder en la posguerra. Para ellos el sector privado era el motor del crecimiento económico y una relación de cooperación con Estados Unidos un horizonte de prosperidad. En este arreglo los sindicatos quedaron sujetos a la autoridad presidencial y la Iglesia católica se convirtió en una leal colaboradora del Estado.

En la posguerra la acelerada transformación social y las tensiones de un mundo que parecía estar al borde de una guerra nuclear, justificaron la concentración del poder que acarreó el desarrollo del PRI y del presidencialismo, la defensa de un orden social jerarquizado y el control de la participación y de la representación política independientes. Así se formó un sistema político de pluralismo limitado que tenía tres piezas claves: el intervencionismo estatal, la presidencia de la República y el partido hegemónico, PRI. ${ }^{14}$ Este sistema desalentaba la participación política, de suerte que la estabilidad descansaba, sobre todo, en el conformismo, la participación controlada y la represión.

\footnotetext{
${ }^{14}$ El autoritarismo de los años cincuenta era muy similar al arreglo de la dictadura franquista: el poder no era monolítico, pero el pluralismo era limitado y carecía de una ideología articulada y homogeneizadora. Véase Linz, "Teoría del régimen autoritario", pp. 205-226; Payne, Política y sociedad en la España del siglo XX, pp. 205-226.
} 
La alianza político ideológica con Estados Unidos era la piedra angular de la estabilidad de esa coalición y el anticomunismo un punto de convergencia en el que se cerró la distancia histórica que hasta entonces había hecho del antiyanquismo uno de los temas centrales del conservadurismo mexicano. Sin embargo, en la posguerra la influencia de Estados Unidos se instaló gradualmente en el terreno de las ideas y de la cultura a expensas de Europa, que hasta entonces había sido una alternativa al poderoso empuje de la cultura popular estadounidense. Muchos mexicanos resentían este fenómeno y se aferraban a la doctrina nacionalista, otros buscaron en la España franquista una alternativa cultural con la esperanza de protegerse del imponente modelo estadounidense. ${ }^{15}$ En 1947 Daniel Cosío Villegas escribió que la influencia cultural de Estados Unidos había machacado la identidad mexicana. Había cambiado todo: la comida, la moda, las ideas políticas, el lenguaje, las artes, la educación “en toda acción interior y exterior". Era "como el Dios de los cristianos: omnipotente y omnipresente". ${ }^{16}$

De manera inevitable, la doctrina nacionalista tenía un componente antiEstados Unidos ${ }^{17}$ que podía traducirse en

${ }^{15}$ México no había reconocido a la dictadura franquista. Paradójicamente, la relación bilateral con España era muy intensa tanto en el ámbito comercial como en el intercambio de estudiantes, deportistas y religiosos. Las industrias editorial y cinematográfica españolas vivieron un periodo de auge en toda América Latina. Véase Loaeza, "Mexico in the fifties". ${ }^{16}$ Cosío Villegas, “México y Estados Unidos”, p. 202.

17 Andrew Paxman sostiene la muy interesante hipótesis de que el Estado mexicano promovió la televisión y abandonó el cine en los años cuarenta y cincuenta porque, aun cuando las series estadounidenses inundaron las pantallas de televisión, para entonces el objetivo central del gobierno era contener a las masas y ya no tanto promover la identidad nacional, 
antiimperialismo. Con frecuencia, las protestas contra Washington derivaban en fórmulas pro comunistas o pro soviéticas, inspiradas sólo por el principio de que "El enemigo de mi enemigo es mi amigo".

El comunismo era débil en México, pero la atmósfera de tensión que generaba el contexto internacional provocaba nerviosismo en una opinión pública reactiva a la supuesta amenaza de una conspiración "roja”. Así lo demostró la crisis guatemalteca que soliviantó al anticomunismo mexicano y dio rienda suelta a sus prejuicios y temores. En julio de 1954, como reacción a la llegada de los arbencistas en busca de refugio a la embajada mexicana en Guatemala, la opinión pública fue bombardeada diariamente por el PAN y por otros partidos minoritarios - el Partido Nacionalista Mexicano - con propaganda anticomunista, y con denuncias en la prensa contra el gobierno y las "células rojas" incrustadas en la Secretaría de Relaciones Exteriores, en la Secretaría de Educación, en la Secretaría de Hacienda y hasta en la Secretaría de Recursos Hidráulicos. Las autoridades buscaban tranquilizar a la opinión cuando aseguraban que el gobierno estaba atento a los movimientos de los comunistas mexicanos y extranjeros, que el Estado Mayor presidencial tenía expedientes completos de cada uno de ellos, "por lo que el gobierno en cualquier momento puede extirpar la penetración comunista y paralizar cualquier acción que emprendan". ${ }^{18}$ La propaganda anticomunista no

como durante el cardenismo. Paxman, "Cooling to cinema and warming to televisión”, pp. 299-320.

${ }^{18}$ Los citados expedientes habrían sido integrados por "un cuerpo de investigadores especializados". "Perfecto control de los rojos y 
veía en estas estrategias una tendencia antidemocrática, más bien las justificaba con el argumento de que el desorden y el conflicto que acompañaban a la excesiva politización o la activación de nuevos actores favorecían la penetración soviética.

La crisis guatemalteca también puso al descubierto actitudes xenofóbicas normalmente contenidas. La llegada a México de los exiliados políticos fue motivo para que sectores de opinión expresaran, ya no sólo las previsibles críticas al peligro que representaban los "extranjeros perniciosos", o a que el país se convirtiera en "basurero de la humanidad”, como lo advirtió el líder empresarial de la Ciudad de México, Honorato Carrasco, ${ }^{19}$ sino desconfianza en general frente a la extranjería. "Consideran que el país está saturado de extranjeros”, informaba la prensa en agosto de 1954. Según el periódico El Informador de Guadalajara, los expertos en población especulaban acerca de la conveniencia de que el país acogiera inmigrantes, pues muchas veces influían "poderosamente en nuestra economía en perjuicio de los connacionales”. La Secretaría de Gobernación respondió a estos señalamientos que nada había que temer, pues la ley en la materia estaba animada "por un espíritu selectivo" que restringía el flujo de extranjeros al país. ${ }^{20}$

sus movimientos”, El Informador (18 jul. 1954), p. 1, año XXXVII, t. CXXXIX, núm. 12968.

${ }^{19}$ Citado en El Informador (14 jul. 1954), p. 1, año XXXVII, t. CXXXIX, núm. 12964.

20 "Diversas opiniones respecto a la inmigración extranjera", El Informador (2 ago. 1954), año XXXVII, t. CXXXIX, núm. 12983. 


\section{El regreso de la Iglesia}

La Guerra Fría fue un fenómeno global que en cada país adquirió los rasgos que le impuso el contexto local. ${ }^{21}$ Así, por ejemplo, mientras en Estados Unidos la propaganda anticomunista hacía hincapié en las libertades individuales, en México era sobre todo una defensa patriótica de la familia y de la religión.

Las circunstancias internacionales pemitieron que la Iglesia católica se reincorporara plenamente al sistema político y contribuyera a la estabilización de una sociedad que experimentaba cambios acelerados. Su reintegración también se justificaba en términos de la defensa de la identidad nacional, porque el catolicismo era un factor central de diferenciación cultural entre Estados Unidos y México. Sin embargo, la Iglesia no dejó de criticar el "modo de vida americano", la liberalidad de las mujeres y la frecuencia del divorcio en ese país. No obstante, en la posguerra se reconcilió con Estados Unidos porque coincidían en el combate al comunismo, que también era la prioridad del Vaticano de Pío XII.

La restauración de la Iglesia católica en el centro de la vida cotidiana de los mexicanos fue un fenómeno político antes que religioso; no obstante, su regreso cobró la forma de un renacimiento de la fe. ${ }^{22} \mathrm{La}$ tregua que introdujo la segunda guerra mundial fue una oportunidad para que se superaran los conflictos de la era revolucionaria y se consolidara una relación de mutuo apoyo. Años antes la jerarquía eclesiástica había aceptado sin titubeos el llamado a la unidad nacional que hizo el presidente Ávila Camacho, pero la

21 Fein, "Producing the cold war in Mexico", pp. 171-213.

22 LoAeza, La restauración de la Iglesia católica, pp. 53-57. 
cooperación con el Estado se afianzó sobre todo en los cincuenta con la cruzada anticomunista, ${ }^{23}$ que hizo de la Iglesia uno de los pilares del régimen autoritario.

Durante el gobierno de Miguel Alemán, en violación de todas las disposiciones constitucionales que prohibían el uso político de la religión y limitaban su presencia pública, se hicieron frecuentes los actos públicos en los que intervenían autoridades eclesiásticas, y no era un secreto que la jerarquía mantenía un diálogo constante con el presidente de la República y con otros funcionarios. En los años cincuenta los hogares mexicanos se vieron inundados de propaganda católica. En 1955 el arzobispo Luis María Martínez declaró en una entrevista con la revista Time de Estados Unidos: "La fe es más fuerte que la ley", y añadió que lo único que faltaba para que la situación de la Iglesia se normalizara, era la reforma a la Constitución. ${ }^{24}$ Entonces se multiplicaron las visitas de representantes del Vaticano a México, las celebraciones religiosas en las calles y la presencia de obispos y sacerdotes en ceremonias cívicas. ${ }^{25}$ Se desarrollaron nuevos vínculos entre católicos mexicanos y estadounidenses;

${ }^{23}$ El 6 de julio de 1949, La Suprema Sagrada Congregación del Santo Oficio expidió un documento que condenaba la pertenencia a algún partido comunista, prohibía la publicación, difusión y lectura de libros, periódicos, revistas y volantes que sostienen la doctrina o la práctica del comunismo. Los comunistas no serían admitidos en los sacramentos y, en caso de que se introdujeran, incurrirían en excomunión.

24 "Religion: Rebirth in Mexico". Entrevista con el arzobispo Luis María Martínez, Time (9 mayo 1955).

${ }^{25}$ Por ejemplo, en marzo de 1945, el arzobispo Sr. Don Luis María Martínez bendijo al Escuadrón 201 antes de su partida al frente del Pacífico. La Iglesia exhortaba a los fieles a que votaran o a que apoyaran al gobierno. Véase "Orientación del señor Arzobispo", La Nación (marzo 1955), año XIV, pp. 3-4. 
el más importante se estableció entre la jerarquía mexicana y el cardenal de Nueva York, Francis Spellman, quien recibió de Pío XII la encomienda de vigilar vicariamente a sus vecinos latinoamericanos. ${ }^{26}$ En la misa dominical una proporción significativa de la población estaba expuesta a los mensajes anticomunistas de la Iglesia. ${ }^{27}$

Pese a todo, la fuerza del conservadurismo no impulsó el desarrollo de una ideología potente o de un partido político fuerte, y los católicos mexicanos quedaron atados a un tradicionalismo extremo. La Iglesia católica hubiera podido ser el núcleo de una alternativa al PRI, pero sus relaciones con el Estado eran tan estrechas y complejas, que las autoridades eclesiásticas no estaban dispuestas a correr el riesgo de una confrontación. Esta prudencia desaconsejaba una posible alianza entre la Iglesia y el Partido Acción Nacional. ${ }^{28}$

\section{El comunismo mexicano en la posguerra}

Eran pocos los elementos objetivos que justificaban la extensión y la intensidad de la ofensiva anticomunista. México

26 "Spellman ayudó a los hermanos Dulles a derrocar al gobierno de Árbenz [...] el 9 de abril de 1954 en todas las iglesias guatemaltecas se leyó una carta pastoral que demandaba al pueblo guatemalteco que se levantara como un solo hombre contra el enemigo de Dios y del país [...]”. Cooney, The American Pope, pp. 234-235.

${ }^{27}$ Las autoridades eclesiásticas apoyaban las propuestas del gobierno y exhortaban a los feligreses a someterse a su autoridad. En 1947, por ejemplo, invitaron al "pueblo" cristiano a participar en la campaña gubernamental contra el analfabetismo y a recibir "con entusiasmo" al presidente de Estados Unidos, Harry S. Truman. Véase Gaceta Oficial del Arzobispado de México, núm. 137 (abr. 1947).

${ }^{28}$ LoAeza, El Partido Acción Nacional. 
había sido el primer país latinoamericano que reconoció al gobierno soviético en 1925, pero las relaciones se interrumpieron cuando la Comintern instruyó al PCM para emprender acciones revolucionarias. ${ }^{29}$ Hubo que esperar el ingreso de México a la segunda guerra mundial para que se reanudaran los intercambios diplomáticos.

El PCM nunca consiguió asumir el liderazgo de la influencia soviética en la clase obrera mexicana, sino que desde el cardenismo se vinculó como un aliado menor al partido en el gobierno. A partir de entonces se desarrolló una relación de dependencia entre los comunistas y la izquierda oficial. Es posible que el PCM haya infiltrado los grandes sindicatos industriales, pero nunca los controló, y por periodos prolongados mantuvo una relación parasitaria con las grandes centrales sindicales, varias de ellas afiliadas al partido en el poder; tampoco eran el interlocutor privilegiado de Moscú; Vicente Lombardo Toledano desempeñaba ese papel desde $1935 .{ }^{30}$

${ }^{29}$ Cárdenas, Historia de las relaciones entre México y Rusia, pp. $193-$ 200; SPEnser, The Impossible Triangle, pp. 95-112.

30 Documentos en los archivos rusos muestran que la Comintern encontró en Vicente Lombardo Toledano "un heraldo de la táctica de Frente Popular más valioso que el PCм [...]”. JeIfets, "Los archivos rusos revelan secretos", pp. 35-64. Véase también Spenser, "Vicente Lombardo Toledano envuelto en antagonismos internacionales”, pp. 251-270. Las autoridades estadounidenses lo consideraban un hombre muy poderoso, y "muy peligroso". Los servicios de inteligencia creían que era el agente soviético número 1 en América Latina. La agencia clasificaba a Lombardo Toledano como neo-communist, y lo asimilaba a las actividades de los comunistas pues sus objetivos políticos, sus técnicas y su línea de propaganda eran "idénticos" a los de las "unidades comunistas que actúan públicamente". CIA, Information Report. Secret, 15 de marzo de 1949, CIA-RDP8200457R002400560012-5. NACP, Md., p. 2. 
El sexenio del presidente Alemán fue la época más dura del anticomunismo mexicano, el PCM vivió en estado permanente de agonía, resultado de una serie de purgas internas y de la represión de que fue objeto. La policía cateaba regularmente sus oficinas, interrumpía sus reuniones y encarcelaba a sus líderes. En consecuencia, era de los más pequeños de América Latina; según un reporte de la CIA, en 1948 sus números eran inciertos, pero en el Distrito Federal registraba menos de 1000 miembros, y en 1958 menos de 5000 en todo el país, mientras que el PC argentino tenía 70000, el PC brasileño 50000 y el PC cubano $12000 .{ }^{31}$ De hecho, la suerte de los comunistas mexicanos dependía en buena medida de sus relaciones con dos personajes, el expresidente Cárdenas y Lombardo Toledano, que no eran comunistas.

El temor a la influencia del comunismo en México que expresaban diplomáticos estadounidenses y británicos se fundaba en que tenía conspicuos simpatizantes en las elites, entre los artistas, los intelectuales, e incluso entre altos funcionarios del gobierno. En enero de 1950 el attaché laboral de la embajada británica en México, A. R. Tennyson, envió al Foreign Office un informe que contenía los nombres de personas y organizaciones cercanas al PCM. En la industria cinematográfica aparecen los nombres de Gabriel Figueroa, Emilio (el Indio) Fernández, María Félix y Dolores del Río. ${ }^{32}$ Entre los

${ }^{31}$ Corporation for Economic and Industrial Research, United StatesLatin American Relations, Soviet Bloc Latin American Activities and their Implications for United States Foreign Policy, Washington, United States Government Printing Office, 1960, p. 25.

${ }^{32}$ Las autoridades de migración de Estados Unidos le negaron visa de entrada a Dolores del Río y a Carlos Chávez en agosto de 1954. Véase Novo, La vida en México en el periodo presidencial de Adolfo Ruiz Cortines, I, pp. 429-430. 
pintores destacan Diego Rivera, David Alfaro Siqueiros, Juan O’Gorman. También hace un recuento de los escritores simpatizantes del PCM, cuando no miembros de ese partido como José Revueltas. Su reporte incluye músicos, cantantes, líderes sindicales, caricaturistas, feministas, profesores universitarios como Manuel Sandoval Vallarta y Leopoldo Zea y, desde luego, políticos influyentes como Cárdenas y Lombardo Toledano. La lista de nombres es larga y sorprendente. ${ }^{33}$ No obstante, el diplomático británico se quedó corto. En los registros del PCM entre los donantes, sostenedores, del periódico $L a$ Voz de México, destacan nombres de altos funcionarios como Gustavo Baz, Walter Buchanan, Alberto Bremauntz, Ricardo J. Zevada, Alfonso Caso, Alfredo del Mazo. ${ }^{34}$

Para las agencias de inteligencia de Estados Unidos, México no era un país del todo confiable, dada una historia revolucionaria que era continuamente invocada por el presidente, por los líderes del PRI y por los sindicatos. Además, la línea que separaba la doctrina nacionalista de la denuncia antimperialista era tenue. Sin embargo, la principal queja de la CIA en relación con el combate anticomunista en México era que, pese a todo, el país era centro de reunión de los comunistas

33 "Communist Organisations in Mexico" Confidential, Memorandum prepared by A. R. Tennyson (Labour Attaché), 18 de enero de 1950. Britannic Majesty's Government, North American Section 3, FO 371/609 55. The National Archives, Kew Gardens.

${ }^{34}$ Partido Comunista Mexicano, Records 1950-1958, Rare Books Collection MS\#0982, c. 5, f. 46-47, Butler Library, Universidad de Columbia. La lista de sostenedores de $L a$ voz de México registra a la casi totalidad del Taller de Gráfica Popular, encabezados por David Alfaro Siqueiros y Manuel Álvarez Bravo; a más de 50 personalidades de la época; incluye también a Lázaro Cárdenas. 
de otros países. ${ }^{35}$ La agencia reportaba que en 1948 había sido escenario de las reuniones comunistas más importantes que habían tenido lugar fuera de la URSS, a las que habían asistido delegados europeos y latinoamericanos. Según la CIA, en ellas se tomaban decisiones que eran "sin lugar a dudas un amenaza para los intereses estratégicos de Estados Unidos". ${ }^{36}$ Ciertamente, los gobiernos mexicanos no ayudaban al PCM, y obstaculizaban sus actividades. Sin embargo, para las agencias de inteligencia México era la "principal área táctica del comunismo en el hemisferio occidental”. ${ }^{37}$ En realidad los agentes estadounidenses no tenían nada que temer en México donde la opción revolucionaria ya era desde entonces, sólo un capítulo de su historia.

\section{Una elite fracturada y una sociedad dividida: cardenismo y anticardenismo ${ }^{38}$}

México era visto desde el exterior como un país ardientemente nacionalista; esta imagen sugería también la existencia

35 En 1949, el informe de la ciA arriba citado, reportaba que nada más en 1948 se habían reunido en México los comunistas cubanos Blas Roca, Juan Marinello y Ladislao Carbajal, el brasileño Roberto, el chileno Salvador Ocampo, el panameño Celso Nicolás Solano y Manuel Mora Valverde de Costa Rica. Habían contactado a Narciso Bassols y a Lázaro Cárdenas. A sus actividades había que añadir las del Partido Comunista Español, que mantenía una campaña antiestadounidense muy intensa. CIA, Information Report. Secret, 15 de marzo de 1949, CIARDP8200457R002400560012-5. NACP, Md., p. 7.

36 CIA, Information Report. Secret, 15 de marzo de 1949, CIARDP8200457R002400560012-5. NACP, Md., p. 21.

37 CIA, Information Report. Secret, 15 de marzo de 1949, CIARDP8200457R002400560012-5. NACP, Md., p. 7.

38 Para una discusión respecto al significado de cardenismo, véase KnIGHT, “¿Cardenismo?”, pp. 73-107. 
de una comunidad estrechamente vinculada, homogénea y más o menos unida. Sin embargo, como se dijo antes, las máscaras del nacionalismo y de las sólidas mayorías de votos que el PRI entregaba a sus candidatos, disimulaban contradicciones y rupturas de índole ideológica, regional, socioeconómica. La fractura política más sobresaliente era la división entre cardenistas y anticardenistas.

La sustancia del cardenismo eran las políticas que como presidente Lázaro Cárdenas había puesto en práctica y que revitalizaron la revolución mexicana. Movilizó a campesinos y obreros, estimuló su organización, distribuyó tierras, aplicó la legislación del trabajo y nacionalizó la industria petrolera. La imagen del presidente Cárdenas quedó para siempre ligada a la defensa de las clases populares. Sus políticas estaban asociadas al intervencionismo estatal, al anticlericalismo, al control del Estado sobre la educación y al nacionalismo económico. Cárdenas era popular entre los trabajadores, pero impopular entre la burguesía y grandes segmentos de las clases medias.

Las imágenes de Lázaro Cárdenas estaban firmemente ancladas en la imaginación de los mexicanos, lo mismo entre sus detractores que entre sus admiradores; así que al término de su gobierno el expresidente no desapareció de la vida pública. Aunque no todos le reconocían autoridad moral o política, tenía una capacidad de influencia que utilizaba con frecuencia sobre todo, para interceder por trabajadores o campesinos ante el presidente de la República. ${ }^{39}$

39 Por ejemplo, en sus Apuntes, una obra semejante a un Diario, Cárdenas anota el 9 de mayo de 1958 que se entrevistó con el presidente Ruiz Cortines y habló en favor de los maestros en huelga. Numerosas son las referencias a situaciones similares con cada uno de sus sucesores, desde 
Las posiciones y las preferencias de los cardenistas eran más consistentes y estaban mejor articuladas que las de los anticardenistas, que formaban un conjunto más heterogéneo; unos estaban vinculados al sector privado, eran pragmáticos y antiestatistas pero la mayoría se adhería a la cruzada anticomunista porque eran católicos y también porque no querían una confrontación con Estados Unidos. El anticardenismo reunía al PAN con la Unión Nacional Sinarquista - la organización del catolicismo ultraconservador - con la Iglesia y las organizaciones de la iniciativa privada. Pese a sus dimensiones nada despreciables, estos grupos adolecían de una notable debilidad política por la falta de organización y la incapacidad de encontrar un líder de la estatura de Cárdenas o de Lombardo que los unificara. Sólo en coyunturas de crisis, como la que podía provocar el regreso del cardenismo, podían unificarse y hacer a un lado sus diferencias. Una movilización de esta naturaleza hubiera sido una grave amenaza para el gobierno.

El intervencionismo de Washington fue un poderoso incentivo para que Cárdenas volviera a la vida pública. Le preocupaba que la hegemonía estadounidense destruyera la soberanía de los países latinoamericanos. El expresidente asumió la representación de un sentimiento antiestadounidense que fue en aumento conforme pasaba el tiempo y se acumulaba la evidencia de que era muy poco lo que Estados Unidos estaba dispuesto a hacer por el desarrollo latinoamericano. ${ }^{40}$ La crítica de Cárdenas atraía a muchos que se

Miguel Alemán hasta Adolfo López Mateos. CÁrdenas, Obras, I. Apuntes 1957-1966, p. 39.

${ }^{40}$ Pasada la euforia del fin de la guerra mundial y de las grandes expectativas que inspiró la promesa de un mundo nuevo y mejor, los 
habían visto afectados por la política de restricción del gasto público y miraban con alarma el incremento de las inversiones extranjeras. ${ }^{41}$ Sin embargo, el liderazgo cardenista estaba limitado por la contradicción que generaba su presencia en el corazón de la fractura política más importante de la sociedad y su condición de símbolo legitimador del partido en el gobierno y del Estado posrevolucionario.

Pese a todo lo anterior, Cárdenas era un político cauteloso que evitaba los enfrentamientos, sobre todo con el presidente de la República. Es probable que por esa razón concentrara su energía y su influencia moral en temas internacionales que le ofrecían mayor margen de acción que problemas internos. También es de suponer que el presidente Ruiz Cortines prefiriera que Cárdenas participara en reuniones donde se hablaba de la paz mundial a que discutiera públicamente el salario mínimo en México. La estrategia del presidente de dejar el camino abierto al expresidente en temas internacionales contribuyó a que la política exterior se identificara con sus ideales, y a que se desarrollara un patrón institucional que canalizaba el compromiso de México con la

latinoamericanos pasaron a la frustración que provocó que Estados Unidos se negara a crear un programa de apoyo al desarrollo económico de la región. Este desencanto se expresó en las reuniones interamericanas que tuvieron lugar en Chapultepec en 1945; en Bogotá en 1948; y en Caracas en 1954, y cada vez que había oportunidad.

${ }^{41}$ En los tres primeros años del gobierno ruizcortinista la inversión pública registró aumentos muy moderados: de 1354 millones de pesos en 1953 a 1661 millones de pesos en 1957; fue más importante el incremento de la inversión privada, sobre todo la inversión extranjera directa que entre 1953 y 1957 pasó de poco más de 40000 dólares a 131000 dólares. INEGI, Estadísticas Históricas de México, México, INEGI-INAH, 1985, t. II, pp. 602 y p. 610. 
democracia, o cualquier causa progresista hacia el exterior. De ahí las contradicciones entre la política exterior y la politica interna; el quiebre entre el progresismo de una y el autoritarismo de la otra adquirió un carácter permanente. La izquierda oficial tendió a dedicarse a estos temas, a concentrarse en la SRE,y a ver la política exterior como su territorio reservado, aun cuando admitiera que era sobre todo una válvula de escape. ${ }^{42}$

El expresidente Cárdenas extendió su liderazgo de izquierda nacionalista y antimperialista a Centroamérica y por esa vía se acercó a los comunistas y a la Unión Soviética; también construyó una red de contactos con organismos extranjeros, muchos de ellos vinculados al movimiento comunista internacional. En 1948 fue elegido miembro del Comité de Honor del Congreso de Unidad Sindical y vicepresidente del Consejo Mundial de Paz, una organización promovida por la Unión Soviética. ${ }^{43}$ Además, según el propio Cárdenas, a invitación de "personalidades cubanas" -Juan Marinello, líder del Partido Comunista Cubanoen septiembre de 1949 organizó en la Ciudad de México el Congreso Continental Americano por la Paz, "contra la guerra y en defensa de las instituciones democráticas de América Latina”. ${ }^{44}$ Como se verá más adelante, se involucró

${ }^{42}$ Así ha sido interpretada la política hacia la revolución cubana. Véase Covarrubias, "México y la Revolución Cubana", pp. 25-46; Pellicer, México y la Revolución Cubana. Según Keller, el factor determinante de la política hacia Cuba fue el temor al activismo de la izquierda mexicana. Keller, "A foreign policy for domestic consumption”, pp. 118.

${ }^{43}$ CIA, The World Peace Conference, mayo de 1954, CIA-RDP 78-00915R000300040001-3, NCAP, Md.

${ }^{44}$ Cárdenas, Obras, I. Apuntes 1941-1956, t. II, p. 311. 
activamente en la defensa del presidente Árbenz y apoyó la Sociedad de Amigos de Guatemala que formaba parte de una red con presencia en casi toda América Latina, creada con ese fin en noviembre de 1953 y en 1955 recibió el Premio Stalin de la Paz.

El activismo de Cárdenas alertó a sus adversarios. Los dos periódicos de mayor circulación en la capital de la República, Excelsior y El Universal y algunos diarios de provincia como El Informador de Guadalajara, denunciaban su participación en la vida pública. La Nación, el semanario conservador identificado con el PAN, ofrece un amplio repertorio de los ataques contra el expresidente. En junio de 1954, en plena crisis guatemalteca, la revista denunció que su verdadero interés era establecer un "Estado comunista". ${ }^{45}$ Según La Nación, Cárdenas utilizaba los acontecimientos guatemaltecos para promover un movimiento pro comunista; por esa razón, decía, había inundado el país de declaraciones y protestas para sembrar la inquietud en el campo. ${ }^{46} \mathrm{Como}$ en el pasado, veían en el cardenismo un "hervidero de agitadores” y en Cárdenas la personificación de la influencia soviética en México.

El homenaje luctuoso a Frida Kahlo, que tuvo lugar en Bellas Artes el 14 de julio de 1954, desencadenó una tormenta política que revela la excitada animadversión hacia el expresidente Cárdenas, y la profundidad de la fractura en la elite política. Durante la ceremonia manos anónimas colocaron sobre el féretro de la pintora una bandera soviética

45 "Lo que importa a Cárdenas es la conspiración internacional de siniestra”, La Nación (20 jun. 1954), vol. xxvi, núm. 662, p. 3.

46 "Lo que importa a Cárdenas es la conspiración internacional de siniestra”, La Nación (20 jun. 1954), vol. xxvi, núm. 662, p. 3. 
en el momento en que el director del INBA, Andrés Iduarte, hacía una guardia. ${ }^{47}$ Cuando los periódicos publicaron la fotografía de ese momento se levantó una ola de furibundas protestas contra el funcionario, denuncias contra la SEP, y varios altos funcionarios en otras Secretarías. Tanto así que la Comisión Permanente del Congreso contra la Intervención del Comunismo en América Latina anunció que llevaría a cabo una investigación. Simultáneamente aparecieron en la prensa insinuaciones de malversación de fondos en la Comisión del Tepacaltepec, que involucraban a su vocal ejecutivo, el expresidente Cárdenas.

El Congreso de Michoacán reaccionó indignado en defensa de Cárdenas, quien presentó su renuncia al presidente Ruiz Cortines al día siguiente del escándalo del INBA. ${ }^{48}$ Los diputados en Morelia exigieron que el supuesto culpable de la calumnia, Rogerio de la Selva - que había sido secretario privado del presidente Alemán y que era nicaragüense - fuera expulsado del país y se le confiscaran sus bienes. Lo calificaban de extranjero malagradecido y rechazaban la campaña "de los sectores reaccionarios, los traidores sinarquistas y los ladrones aliados del imperialismo". Añadían que su objetivo era dividir al sector revolucionario "con fines inconfesables". ${ }^{49} \mathrm{Al}$ día siguiente enviaron una circular

${ }^{47}$ Para una descripción detallada de este incidente véase Novo, La vida en México en el periodo presidencial de Adolfo Ruiz Cortines, pp. 416-417. ${ }^{48}$ En sus Apuntes Cárdenas escribe que los ataques en su contra eran tan violentos que temió perjuicios al gobierno. Para liquidar este enojoso asunto, el presidente Ruiz Cortines hizo un público reconocimiento al expresidente Cárdenas por los servicios rendidos "a la patria”. CárDENAS, Obras, I. Apuntes 1941-1956, pp. 372-373.

49 "La renuncia de Cárdenas", El Informador (29 jul. 1954), primera plana, año XXXVII, t. CXXXIX, núm. 12979. 
a los demás congresos estatales para invitarlos a secundar su petición al secretario de Gobernación, Ángel Carbajal.

El 30 de julio la prensa anunció, "en lacónico boletín”, que la presidencia de la República no había aceptado la renuncia del expresidente, quien había sido exonerado del cargo de comunista o filocomunista, porque "ningún funcionario del gobierno de México ostenta una ideología contraria a los intereses de la patria". ${ }^{50}$ El PAN y la uNs lamentaron la cancelación de la decisión que habían aplaudido el día anterior. Sin embargo, el hecho importante había sido la visita del siempre conciliador expresidente Manuel Ávila Camacho, el mismo 28 de julio a Cárdenas, probablemente para convencerlo de que reconsiderara la renuncia.

También el 30 de julio, el antiguo ministro de Recursos Hidráulicos de Miguel Alemán, Adolfo Orive de Alba, publicó un largo artículo sobre la Comisión del Tepalcatepec en el que describía el brillante desempeño de su vocal ejecutivo, Lázaro Cárdenas, quien había cumplido con creces con el programa establecido, además de que había entregado cuentas claras. Mencionaba de paso que el expresidente había sido designado en esa posición por el entonces presidente Miguel Alemán.

El antagonismo cardenismo-anticardenismo trascendió al propio Cárdenas. Se convirtió en una fractura histórica, un rasgo definitivo del escenario político de la segunda mitad

50 "No le fue aceptada la renuncia al general Cárdenas", El Informador (30 jul. 1954), primera plana, Año XXXVII, t. CXXXIX, núm. 12980; "No fue aceptada al Gral. Cárdenas su renuncia como vocal de Tepalcatepec", Excelsior (30 jul. 1954), Sección A, primera plana; "Ruiz Cortines no aceptó la renuncia de Cárdenas”, El Universal (30 jul. 1954), Sección Primera, primera plana. 
del siglo xx en México y un eje de organización de actitudes y preferencias políticas. En contextos de intensa politización, la fractura se hacía evidente y era una referencia para el conflicto del momento. En 1954 desempeñó este papel en la disputa anticomunismo-comunismo; en 1961 fue el fundamento del Movimiento de Liberación Nacional (MLN), que nació en respuesta a la revolución cubana, y en 1988, cuando por fin se liberó de sus orígenes priistas, representaba el rechazo al neoliberalismo. Al inicio del siglo xxI sigue siendo un referente para todas las fuerzas políticas.

MÉXICO EN LA POLÍTICA DEL PRESIDENTE EISENHOWER HACIA AMÉRICA LATINA

En 1952, durante la campaña electoral, el presidente Eisenhower anunció una "política exterior positiva" cuyo principal objetivo era frenar el expansionismo soviético, así como recuperar las áreas en las que había establecido su influencia. ${ }^{51}$ En América Latina el vértice de esta política fue el anticomunismo, "el abrazo sin cortapisas a las dictaduras militares anticomunistas y la nula disposición a criticar la represión política y civil" en estos países. ${ }^{52}$ De haber

${ }^{51}$ Rabe, Eisenhower and Latin America; Craig y Logevall, America's Cold War. Citado en Patch y Richardson, The Presidency of Dwight D. Eisenhower, p. 75.

52 RaBE, Eisenhower and Latin America, pp. 40-41. "América Latina tenía que apoyar la política exterior anticomunista de Estados Unidos. Cualquier desvío de la visión estadounidense del orden mundial apropiado era una amenaza para la seguridad de Estados Unidos y para el equilibrio de poder global. Estados Unidos tenía el derecho de corregir este mal comportamiento". Rabe, The Killing Zone, p. 35. 
leído con atención los discursos de campaña de Eisenhower, Árbenz habría sabido que su destino estaba escrito.

Desde el inicio de su primera administración, Eisenhower mostró especial interés en los problemas de América Latina, comisionó distintos estudios - nombró a su hermano Milton director de dos de ellos-, sostuvo encuentros bilaterales con los presidentes latinoamericanos y en 1955 organizó una Conferencia Interamericana de presidentes, que tuvo lugar en Panamá. Su política exterior revela la mirada de un militar cuyas consideraciones de índole estratégica y geopolítica estaban firmemente enclavadas en la Doctrina Monroe que resucitó la Guerra Fría. ${ }^{53}$ Esta característica favoreció las relaciones con México durante su administración. El presidente estadounidense hablaba con frecuencia de la conveniencia de promover la cooperación bilateral con un país

${ }^{53}$ Un documento firmado por el Comando Militar Conjunto se incluyó en las conclusiones de la Conferencia Inter-Americana de Chapultepec que se celebró en México en febrero de 1945, estipulaba que el hemisferio occidental era una "entidad militar" cuya integridad era vital para la seguridad de Estados Unidos. Leffler, "The American conception of national security”, pp. 346-381. En las academias militares de Estados Unidos a los cadetes se les enseñaba los tres imperativos de las relaciones con el mundo exterior: los territorios americanos estaban cerrados a cualquier colonización por parte de los países europeos; Estados Unidos no habría de involucrarse en las guerras europeas; y cualquier intento por parte de Europa de extender su sistema político al hemisferio sería considerado una amenaza para la paz y la seguridad de Estados Unidos. Sмітн, The Last Years of the Monroe Doctrine, p. 3. En octubre de 1962, en plena crisis de los misiles, el congresista de Arizona, John J. Rhodes, declaró: "La Doctrina Monroe, que cada uno de los miembros de este cuerpo, aprendió de niño en la escuela, es una tradición americana tan sagrada como la Constitución y la Declaración de Independencia". Citado en Smith, The Last Years of the Monroe Doctrine, p. 4. 
que para ellos era distinto de los demás, por el simple hecho de que compartía con el suyo una frontera de 1800 millas. ${ }^{54}$

En la década de los cincuenta, la Guerra Fría tuvo efectos contrastados sobre la relación entre México y Estados Unidos. El conflicto soviético-estadounidense acentuó el valor estratégico del territorio mexicano y el gobierno de Ruiz Cortines pudo beneficiarse de la posición del país dentro del perímetro de seguridad de Norteamérica para obtener un trato diferente al que recibían otros países de la región. Sin embargo, la rivalidad soviético-estadounidense también aumentó las restricciones "a [la] libertad de acción política", ${ }^{55}$ del gobierno mexicano, pues el deterioro del clima entre las superpotencias, la agudización de las tensiones internacionales y la sombra de la amenaza nuclear, redujeron sus oportunidades dentro y fuera del país.

Desde el gobierno del presidente Ávila Camacho, la estrategia mexicana para lidiar con el poderoso vecino consistía en dos vías: primero, México asumió las principales restricciones que se derivaban de la contigüidad territorial, como inevitables, y a partir de ellas definió sus opciones. Por ejemplo, se mantuvo a distancia de la Unión Soviética y descartó

${ }^{54}$ En agosto de 1953, el embajador en Washington, Manuel Tello, reportó al secretario de Relaciones Exteriores, Luis Padilla Nervo, la visita de cortesía del expresidente mexicano Abelardo L. Rodríguez al presidente Eisenhower. Según éste, las relaciones que deseaba cultivar con México [y Canadá] no tenían el mismo significado que con otros países de América Latina "ya que la geografía nos ha hecho vecinos y querámoslo o no (son sus propias palabras) este hecho marca en forma ineludible nuestras relaciones". "Embajador Manuel Tello al C. Lic. Luis Padilla Nervo, Secretario de Relaciones Exteriores, AGE, SRE, exp. 111/321.2 (42'73) f. 23783 (4 de agosto de 1953).

55 OJeda, Alcances y límites, p. 92. 
el socialismo como alternativa para un país que era el vecino contiguo del más feroz adversario de esa ideología y de esa forma de régimen político. ${ }^{56}$ En segundo lugar, se acogió a la doctrina nacionalista y al compromiso con la democracia para fincar una comunidad de valores y una ideología que compartía con Estados Unidos. Un primer paso en esa dirección fue la reforma electoral y partidista de 1945-1946 que modificó el régimen político para ajustarlo en la forma a las expectativas democráticas de Washington. ${ }^{57}$ Con toda naturalidad, el anticomunismo se incorporó a los temas del nuevo partido.

En 1954 la relación entre Estados Unidos y México era esencialmente buena. Había algunos temas específicos que provocaban fricciones entre ellos, sobre todo el relativo a los trabajadores mexicanos que cruzaban ilegalmente la frontera. ${ }^{58}$ El modelo de desarrollo económico también era motivo de discusión. Eisenhower creía firmemente en el libre comercio. Su lema era "Comercio, no ayuda" (Trade, not aid). ${ }^{59}$ Durante su gobierno los fondos de financiamiento para América Latina del Eximbank, registraron una violenta caída de 147 millones de dólares en 1952 a 7.6 millones en $1953 .{ }^{60}$

${ }^{56}$ El mismo tipo de restricciones pesaron sobre el gobierno mexicano a finales del siglo xIx. Friedrich Katz muestra cómo Porfirio Díaz y sus "científicos" vivían permanentemente conscientes de la amenaza que representaba su poderoso vecino del norte. Creían que dos tipos de fenómenos podían desencadenar una intervención estadounidense: inestabilidad interna que amenazaba sus intereses en México, y un compromiso con otra potencia extranjera. KaTz, The Secret War in Mexico, pp. 27-28. ${ }^{57}$ Loaeza, "La reforma política de Manuel Ávila Camacho", pp. 251-345.

${ }^{58}$ Véase Torres, México y el mundo, t. VII, pp. 99-122.

59 Véase Sewell, "A perfect (Free-Market) world?”, pp. 841-848.

${ }^{60}$ SEwell, “A perfect (Free-Market) world?”, p. 66. 
En términos más amplios el nacionalismo económico mexicano también era una fuente de irritación para los funcionarios estadounidenses que insistían en la eliminación de las barreras al comercio, o de restricciones a las inversiones extranjeras. En este respecto, el presidente Ruiz Cortines se mostró tan intransigente como lo serían sus sucesores. Defendió el proteccionismo y el intervencionismo estatal, que eran dos presupuestos fundamentales del modelo de desarrollo. Las posiciones mexicanas ante la crisis entre Estados Unidos y Guatemala también provocaron cierta irritación. No obstante, como se verá más adelante, Ruiz Cortines colaboró tanto como pudo con Washington, dentro de las limitaciones que le impuso la fractura interna y su propia desconfianza hacia Estados Unidos.

En octubre de 1953, cuando se aceleraban los preparativos del golpe contra Árbenz, Eisenhower invitó a su contraparte mexicana a la inauguración de la presa Falcón, en la frontera entre Texas y Tamaulipas. En este encuentro, el estadounidense describió la relación entre los dos países como "el tipo de amistad que busca, busca seriamente y con insistencia entender el punto de vista del otro, y luego se empeña con todo lo que tiene en el corazón en entender el punto de vista de su amigo". ${ }^{61}$ Se refirió a las necesidades específicas de asistencia técnica, oportunidades educativas y de capital de México. La respuesta de Ruiz Cortines fue una recitación de principios generales y abstractos. Aludió a las amenazas a la paz internacional, a la soberanía nacional y a la autodeterminación como los temas prioritarios de la agenda mexicana, como si el

61 "Text of talks by Eisenhower and Ruiz Cortines at the dedication of Falcon Dam in Texas", The New York Times (20 oct. 1953). 
fantasma de la intervención sobrevolara la reunión. Es posible que Ruiz Cortines haya seguido esa vía por influencia de la coyuntura inmediata en la que se acercaba la tormenta sobre el presidente Árbenz. Habría, sin embargo, que recordar que la reflexión abstracta era una estrategia muy socorrida de los presidentes mexicanos que así evadían posibles confrontaciones con el poderoso vecino. ${ }^{62}$

Eisenhower hablaba el lenguaje de la cooperación, pero no obtuvo ninguna respuesta de parte de Ruiz Cortines. Si el estadounidense estaba realmente ofreciendo un programa de ayuda económica, esta reunión fue una oportunidad perdida para ampliar la relación bilateral. En lugar de eso, los discursos presidenciales fueron monólogos paralelos. Sólo en un tema coincidieron los presidentes en forma explícita: la necesidad de combatir el comunismo y de preservar la estabilidad política mexicana que, dijeron, era para ambos una prioridad..$^{63}$

${ }^{62}$ En general, los presidentes mexicanos rehuían la discusión directa de temas puntuales con sus contrapartes estadounidenses. Preferían mantenerse en un nivel abstracto y dejar a sus subalternos, o al tiempo, la solución de los problemas. Pellicer, "México en la oeA".

${ }^{63}$ Un Memorandum firmado por el entonces embajador de Estados Unidos en México, William O’Dwyer, es una muestra del tipo de apoyo que el gobierno mexicano recibía de Washington para defender el status quo. En enero anterior los gobiernos habían iniciado pláticas a propósito de un tratado militar. Después de semanas de discusiones infinitas, el embajador mexicano en Washington, Rafael de la Colina, explicó que era muy difícil para el gobierno firmar un acuerdo de esa naturaleza en mitad de una campaña electoral. El gobierno de Alemán ya había sido acusado de "venderse" a Estados Unidos. De la Colina sugería que se pospusiera hasta después de la elección de julio. Para entonces se habría aclarado la atmósfera política y el PRI sería más fuerte. La sugerencia del mexicano fue aceptada. Embajador Rafael de la Colina y Embajador William O’Dwyer, "Memorandum of conversation", 20 de febrero de 1952. 
El comunicado oficial del encuentro en presa Falcón enfatizaba las coincidencias en la evaluación de los presidentes de la situación internacional y su compromiso con una paz duradera. También hablaba de su propósito de "cooperar con otras repúblicas en el hemisferio en la promoción de los grandes principios de la democracia que constituyen la herencia común de las naciones americanas”. ${ }^{64}$ Las implicaciones de esta declaración fueron más claras en la X Conferencia Interamericana que tuvo lugar en febrero del año siguiente.

En opinión del secretario Dulles, entre México y Estados Unidos se había generado un equilibrio de expectativas. En un Memorándum que preparó para el presidente Eisenhower poco antes del encuentro presidencial, escribió: "Sabemos qué podemos esperar de México y entendemos sus limitaciones. Lo mismo puede decirse de la actitud de México hacia Estados Unidos, aunque tradicionalmente ha estado coloreada por vagas sospechas respecto a nuestras motivaciones”. ${ }^{65}$ En la atmósfera de la época, la ambivalencia frente a la "ofensiva soviética”, el anticomunismo, o el papel del Estado en la economía, podía haber provocado

Citado en "Editorial note", Foreign Relations of the US. The American Republics, 1952-1954, vol. Iv, doc. 572, p. 1330.

64 Citado en Casasola Zapata, Historia Gráfica de la Revolución Mexicana, 1900-1970, p. 2808.

65 "Memorandum by the Secretary of State to the President" (13 de octubre de 1953), Foreign Relations of the United States, 1952-1954, Washington, Government Printing Office, 1983, p. 1350. Es probable que por motivos familiares, el secretario de Estado tuviera un mejor conocimiento de México que de otros países latinoamericanos. Su abuelo, John Watson Dulles, fue embajador en México de 1873 a 1880. Su hijo, John W. F. Dulles (1913-2008) era un académico especialista en México; es el autor de Yesterday in Mexico, un libro de entrevistas a algunos de los líderes más prominentes de la revolución mexicana. 
tensiones en la relación bilateral. No obstante, Dulles consideraba que los planteamientos mexicanos reflejaban más bien un "liberalismo extremo" y que si bien la revolución mexicana tenía tendencias socialistas, no era marxista ni tenía contacto con los soviéticos. En su opinión, el PRI era un partido capitalista, y concluía "no hay duda de que en un momento de crisis México estaría de nuestro lado". ${ }^{66}$ Siendo así, Estados Unidos podía permitirle sus juegos retóricos.

\section{México ante la intervención de Estados Unidos en Guatemala}

La conspiración contra el gobierno arbencista fue, según el embajador mexicano Luis Quintanilla, un "secreto de polichinela", ${ }^{67}$ porque se habló de ella incesantemente desde 1952. Además de la Casa Blanca y del Departamento de Estado, los senadores estadounidenses también se ocuparon de Guatemala, convencidos de que había que hacer "lo que fuera necesario" para detener la supuesta agresión soviética en Centroamérica. ${ }^{68}$ La prensa estadounidense era explícita e insistía en que el comunismo se había apoderado de Guatemala. También sostenía que el gobierno estadounidense preparaba una respuesta; por ejemplo,

\footnotetext{
66 "Memorandum by the Secretary of State to the President" (13 de octubre de 1953), Foreign Relations of the United States, 1952-1954, Washington, Government Printing Office, p. 1351.

${ }^{67}$ Memorandum ultraconfidencial, "Revelaciones hechas por el presidente de Nicaragua, General Anastasio Somoza, al embajador Luis Quintanilla, presidente de la Comisión de Investigación de la O.E.A.”, AGE, SRE, exp. L. Quintanilla, c. 6, vol. 20 (17 de enero de 1955).

${ }^{68}$ Barrett, "Sterilizing a Red Infection", p. 24.
} 
en enero de 1954, la revista Time citaba una declaración del nuevo embajador estadounidense ante el gobierno de Árbenz, John Peurifoy, quien afirmó que si la situación guatemalteca se seguía deteriorando, Estados Unidos tendría que actuar incluso unilateralmente: "La opinión pública en Estados Unidos podría forzarnos a tomar medidas para evitar que Guatemala caiga en el regazo del comunismo internacional. No podemos permitir que se establezca una república soviética entre el Canal de Panamá y Texas”. ${ }^{69}$

El 1ํ de marzo se inauguró la X Conferencia Interamericana de Caracas. La reunión estaba programada para discutir temas económicos. Sin embargo, el secretario de Estado Dulles la utilizó para movilizar el apoyo de los países latinoamericanos y poner fin a la experiencia reformista en Guatemala. El presidente Árbenz había incluido en su gabinete a connotados comunistas y había puesto en práctica una reforma agraria que afectaba los intereses de la oligarquía y de empresas como la United Fruit Company. A ojos de Washington, estas medidas ponían en peligro la estabilidad del orden hemisférico porque abrían la puerta a la influencia soviética.

El secretario Dulles presentó una resolución que estipulaba que "el control de las instituciones políticas de cualquier Estado americano por el movimiento comunista internacional [...] sería una amenaza a la paz de América” y, en referencia al Tratado de Río de seguridad colectiva de 1947, advertía que la respuesta a dicha amenaza sería una "acción apropiada de acuerdo con tratados existentes" ${ }^{70}$

69 “The Americas: the problem of Guatemala”, Time (11 ene. 1954).

70 Department of State, Intervention of International Communism in Guatemala, Westport, Conneticut, Greenwood Press Publishers, 1954. 
En la sesión plenaria del 8 de marzo, el secretario mexicano de Relaciones Exteriores, Luis Padilla Nervo, defendió los principios de autodeterminación y la no intervención, con argumentos claros y consistentes pero en términos generales y abstractos, sin mencionar al gobierno de Árbenz. ${ }^{71}$ Señaló que la resolución propuesta por el secretario Dulles violaba los principios de la Constitución mexicana y abría la puerta al intervencionismo. Propuso dos enmiendas: la primera, hablaba del "comunismo internacional" como cualquier otra doctrina política que no representaba en sí misma una amenaza y que no tenía vínculos con ningún país en particular. La segunda proponía que se respetara la soberanía de los Estados para que definieran según sus normas constitucionales los términos del combate contra el comunismo. Ambas enmiendas fueron rechazadas.

Dulles presionó despiadadamente a los delegados latinoamericanos para comprometerlos con su propuesta. "Lo hizo de tal manera que perdió amigos y alienó a los pueblos al sur del hemisferio". ${ }^{72}$ Prácticamente ninguna delegación pudo resistir sus amenazas veladas de represalias comerciales. ${ }^{73}$

71 En la Conferencia de Caracas, la oea fue un instrumento de Estados Unidos. La diplomacia mexicana, decepcionada, optó por expresarse en términos puramente jurídicos. "Aún en los momentos álgidos de las relaciones interamericanas, México se ha abstenido de fundamentar sus posiciones aludiendo a los problemas políticos que dominaban el panorama continental”. Pellicer, "México en la oeA", pp. 288-302, p. 290.

72 Connell-Smith, The Inter-American System, pp. 162-164. El representante de Uruguay declaró que había votado "sin entusiasmo, sin optimismo, sin alegría y sin el sentimiento de que contribuíamos a adoptar una medida positiva. Citado en ConNell-Smith, The Inter-American System, p. 163.

${ }^{73}$ Según un miembro de la delegación de Estados Unidos, los latinoamericanos "nunca habían estado tan bien preparados" para una confe- 
El 13 de marzo fue votada la Resolución XCIII denominada "Declaración de Solidaridad para la Preservación de la Integridad Política de los Estados contra la intervención del Comunismo Internacional”. Obtuvo 17 votos a favor; Guatemala votó en contra; Argentina y México se abstuvieron. ${ }^{74}$ Prácticamente todos los delegados convinieron en que el comunismo no tenía cabida en el hemisferio, pero también rechazaron de manera unánime el intervencionismo implícito en la resolución. ${ }^{75}$

De regreso en Washington, Dulles explicó al National Security Council que la posición mexicana había sido "desafortunada” pero, "por suerte", Padilla Nervo "no se tomó muy a pecho" la oposición a la resolución, pues tenía tanto prestigio que si hubiera querido, hubiera podido poner en aprietos a la delegación estadounidense. Dulles abundó: “La verdadera explicación de la posición mexicana es la situación

rencia interamericana. Su actitud sugería que estaban dispuestos a negociar con Estados Unidos el apoyo al aislamiento de Guatemala, a cambio de mejores términos de intercambio, reducción de tarifas a las importaciones latinoamericanas y una política crediticia más liberal. No obstante, la delegación estadounidense tenía bien claras las instrucciones de que no negociaba temas políticos con concesiones en el ámbito económico. "Report prepared in the Department of State", FRUS, vol. iv, the American Republics(abril de 1954).

${ }^{74}$ SRE, México en la Xa Conferencia Inter-Americana, México, Secretaría de Relaciones Exteriores, 1954, p. 16.

75 "La Décima Conferencia panamericana implicó un punto de inflexión en la historia de la OEA, e introdujo la clave anticomunista como argumento del Departamento de Estado para legitimar su intervencionismo en los asuntos internos de otros países. Es imposible entender la expulsión de Cuba de la OEA en 1962 o la posterior intervención en República Dominicana en 1965. La conferencia de Caracas fue un episodio clave para entender el inicio de la Guerra Fría en América”. Morgenfeld, "El inicio de la Guerra Fría”, pp. 75-97. 
política interna. Los mexicanos todavía son muy susceptibles a la menor posibilidad de interferencia de Estados Unidos en los asuntos mexicanos". ${ }^{76}$ Lo cierto es que todos quedaron insatisfechos de la reunión de Caracas, pues pese a haber obtenido los votos que necesitaba, para el secretario Dulles no fue una victoria limpia.

Hasta el fin de la administración Eisenhower, no hubo un solo indicio de tensiones en la relación bilateral que pudieran atribuirse al voto mexicano en Caracas. Por consiguiente, sería éste un buen ejemplo del acuerdo para disentir al que se refiere Ojeda. Sin embargo, documentos oficiales de ambos países muestran que el supuesto respeto a la política exterior autónoma era más bien respeto de la Casa Blanca a la simulación del presidente mexicano ante su opinión pública.

\section{La duplicidad mexicana}

En condiciones normales la opinión pública mexicana era indiferente a la política internacional, ${ }^{77}$ sin embargo, en el caso guatemalteco la alertaron las minorías activas de izquierda que marchaban en las calles para exigir al gobierno

${ }^{76}$ National Security Council, Memorandum of discussion at the $189^{\text {th }}$ Meeting of the National Security Council, Document 77 (18 de marzo de 1954). FRUS, 1952-1954, the American Republics, vol. Iv.

77 Según Jorge Castañeda de la Rosa, en los años cincuenta y sesenta un “nacionalismo exagerado" fomentaba esa indiferencia: "Desde la Revolución mexicana, hay algo similar a la introspección nacional [...]. El nacionalismo se ha manifestado en México y en todas partes, en un muy bajo nivel de involucramiento, incluso en rechazo, en la opinión pública y en círculos gubernamentales a cuestiones generales de naturaleza amplia que si se posponen no crean un problema interno inmediato". México y el orden internacional, p. 14. 
que defendiera a Árbenz. ${ }^{78}$ Manuel Gómez Morín, presidente del PAN, no exageraba cuando en junio de 1954 escribió que la invasión a Guatemala era "el tema más importante para la opinión pública". ${ }^{79}$ No obstante, la causa no atrajo apoyo unánime. ${ }^{80}$ Muchos creían que Guatemala era el centro de un plan subversivo. La revista La Nación denunciaba la intención de los "comunistas criollos" de someter al país al comunismo internacional, e insistía en que había que "extirpar" las células comunistas incrustadas en el medio universitario y en la Secretaría de Relaciones Exteriores.

Unos días antes de la invasión, el presidente del PRI, Gabriel Leyva Vázquez, sostuvo que "[...] el PRI se siente en actitud de declarar categóricamente que en México se tienen como bandera los principios democráticos de la Constitución de 1917 y se rechazan todas las ideas y los postulados que a ella se oponen. Siendo así, el Partido declara que repudia el comunismo y cualquier otro totalitarismo que pugne con su ideología". ${ }^{81}$ Esta era muy probablemente la opinión

78 Buchenau, "Por una Guerra Fría más templada”, pp. 135-136.

79 Manuel Gómez Morín, "Guatemala entre dos imperialismos", La Nación (20 jun. 1954), vol. xxvi, núm. 662, contraportada.

${ }^{80}$ Incluso la Delegación mexicana en Caracas se dividió. El embajador Castañeda de la Rosa, antiguo secretario de Relaciones Exteriores, asistió a la conferencia cuando era un joven funcionario. Desde Caracas lo mandaron a la Ciudad de México para que consultara directamente con el presidente Ruiz Cortines, cómo debía votar la delegación. Fue el presidente quien optó por la abstención. Castañeda de la Rosa, en entrevista con Nancy Robinson, "México frente a la crisis de Guatemala en 1954" [en línea] http//www. raco.cat/index.php/boletinamericanista/article/ viewFile/98476/146.119".

${ }^{81}$ Tiempo (21 jun. 1954), vol. xxv. Según el periodista mexicano Carlos Denegri, "Las palabras del general Leyva Vázquez reflejaban fielmente el punto de vista del Primer Mandatario y de su gabinete y constitu- 
del presidente, pues el líder de su partido no era sino su portavoz. En cambio, no eran un secreto las diferencias entre el presidente Ruiz Cortines y el secretario Padilla Nervo. Mucho se hablaba de las "tendencias comunistas" del secretario y de su inminente renuncia, pues, según fuentes de la SRE, la posición de México en Caracas había provocado la devaluación del peso que se anunció en abril, y el presidente estaba "dispuesto a cambiar por completo la orientación que siguió su país en Caracas y [que] desea unirse a Estados Unidos en la lucha abierta contra la penetración extranjera". ${ }^{82}$

El presidente Ruiz Cortines miraba con preocupación el nerviosismo que empezaba a manifestarse en México. Una combinación de los cardenistas con otros descontentos podía ser terreno propicio para que brotaran protestas por otros motivos distintos a la causa de Árbenz: el aumento de los precios de los alimentos, las limitaciones a la libertad de prensa, o el encarcelamiento de los comunistas. En busca de algún tipo de equilibrio, el gobierno patrocinó organizaciones independientes, que no eran más que una etiqueta, ${ }^{83}$ probablemente para compensar la incapacidad

yen una seguridad dada al pueblo mexicano y a los países democráticos de que no ha alterado en lo más mínimo el respeto a los preceptos constitucionales”, Denegri, Carlos, Nuestra opinión (junio de 1954), carta \# 181, año IV, s. p.

82 "México se libró de una posible crisis ministerial" "Padilla Nervo hubiera sido puesto fuera del gabinete", El Informador (17 jul. 1954), año XXXVII, t. CXXXIX, núm. 12967, primera plana.

${ }^{83}$ Se creó un mundo de organizaciones ficticias; por ejemplo, Jorge Prieto Laurens era líder del Frente Popular Anticomunista que distribuía propaganda anticomunista en la calle, organizaba marchas y reuniones de protesta "contra la infiltración soviética". "De Jorge Prieto Laurens y Arturo Amaya (secretario) a Rogerio de la Selva, 21 de mayo de 1952", 
de organización de la derecha y contrarrestar el creciente peso de la izquierda. En la primera semana de junio se inauguró en la ciudad de México el "Primer Congreso contra la Intervención Soviética en América Latina”, en el que participaron representantes de todos los países de la región y de España, pese a que México no tenía relaciones diplomáticas con la dictadura franquista. En la sesión inaugural, Arturo Amaya, quien aparecía como secretario de la Sociedad Pro-Liberación de Guatemala, agradeció el apoyo político $\mathrm{y}$ financiero del presidente Ruiz Cortines. ${ }^{84}$

El 17 de junio de 1954, tropas rebeldes guatemaltecas cruzaron la frontera hondureña con su país bajo la dirección del coronel Carlos Castillo Armas. Tuvieron el apoyo del embajador Peurifoy; y de una guerra psicológica orquestada por la CIA, que consistió en hacer creer a los guatemaltecos que la operación estaba respaldada por numerosos refuerzos militares. El ejército temeroso de una invasión de tropas estadounidenses, abandonó a Árbenz. ${ }^{85} \mathrm{El} 26$ de junio la prensa informó que el presidente de Guatemala había renunciado ${ }^{86}$

AGN, $P, M A V, 621-8-2286$. Creó sucesivas organizaciones anticomunistas, todas artificiales, financiadas por el gobierno.

84 “Congreso anticomunista”, Tiempo (7 jun. 1954), vol. xxv, núm. 631, pp. 5-6. Es probable que esta "sociedad" fuera la respuesta del gobierno a la creación de la Sociedad Amigos de Guatemala (SAG) que, según reportes de la CIA, formaba parte de una red impulsada por la Unión Soviética, que se extendía a otros países latinoamericanos. "Progress Report prepared in the Department of State for the Operations Coordinating Board”, doc. 8 (25 de mayo de 1954) FRUS, 1952-1954. The American Republics, vol. IV. 85 Gleijeses, Hope shattered, pp. 329-339.

86 Las descripciones de la crisis muestran un Árbenz empequeñecido, arrinconado y aislado. Luis Cardoza y Aragón hace un retrato cruel del presidente, cuya renuncia le es inexplicable: ¿Cómo se explica la renuncia del presidente Árbenz? ¿Así defendió la soberanía de su patria? ¿Cómo 
y que había pedido asilo para él y su familia en la embajada mexicana.

Era previsible que así ocurriera. México había construido una respetable tradición de asilo de la que se enorgullecían los miembros del servicio exterior. Árbenz y sus partidarios veían en la revolución mexicana un antecedente y un modelo, en particular de su reforma agraria, en cuyo diseño habían participado ingenieros mexicanos. El gobierno arbencista había recibido apoyo del expresidente Lázaro Cárdenas y de Lombardo Toledano. Este último había sido su huésped en varias ocasiones, habían contribuido a organizar la unificación de los sindicatos y había sido orador en grandes concentraciones en las que pronunciaba encendidas arengas antimperialistas. ${ }^{87}$ Era natural que Árbenz y los suyos creyeran que tan influyentes personajes lograrían movilizar la solidaridad de un gobierno con el que compartía ideales revolucionarios. Tanto Cárdenas como Lombardo intentaron presionar al presidente.

Inmediatamente después de la invasión, Ruiz Cortines recibió una carta de Cárdenas en la que le proponía que mediara en el conflicto guatemalteco ${ }^{88}$ Se negó, probablemente consciente de que poco ayudaría su intervención, y más bien tendría un efecto negativo sobre sus relaciones con Washington. Después de esta negativa Cárdenas

pudo haberlo decidido por sí mismo, y justificarlo a sus propios ojos, como si se tratara de la venta de un caballo?". CARdoza y ARAgón, La revolución guatemalteca, p. 198.

87 CIA, Information Report, The Congreso de Unidad Sindical, 21 de diciembre 1951, CIA-RDP82-00457R0094000. NACP, Md. El expresidente Lázaro Cárdenas también era miembro de la wFTU.

${ }^{88}$ Citada en Buchenau, "Por una Guerra Fría más templada”, p. 136. 
optó por dirigirse a la opinión pública y mandó a la prensa las cartas que había enviado, primero al secretario guatemalteco de Relaciones Exteriores, Guillermo Toriello, en la que expresaba su "amistad personal y [mi] simpatía con el pueblo y el gobierno de Guatemala [...] cuya soberanía está amenazada". ${ }^{89}$ Después de la invasión publicó la carta que dirigió al presidente Árbenz en la que hablaba en nombre del pueblo mexicano, expresaba su admiración por la reforma agraria que había emprendido su gobierno y por su defensa de la soberanía nacional. ${ }^{90}$ Es probable que Cárdenas hiciera públicas estas cartas para movilizar a la opinión y así levantar presión sobre el presidente Ruiz Cortines. ${ }^{91}$ Profesores y estudiantes universitarios protestaron en las

89 Tiempo (21 jun. 1954), núm. 635, vol. xxv, p. 3.

90 Tiempo (28 jun. 1954), núm. 636, vol. xxv, p. 23.

91 Entre los papeles personales de Árbenz hay un memorándum ciego con fecha 5 de junio de 1954 que contiene las notas de una conversación de un personaje anónimo con Guillermo Toriello. El documento no está firmado pero es claro que el autor estaba muy familiarizado con las relaciones mexicoguatemaltecas. El documento contiene una lista de tácticas diplomáticas que recomienda para responder a la ofensiva de Estados Unidos. También hay muchas referencias a un "mexicano muy importante y distinguido" que podría promover el involucramiento de México como "mediador amistoso". Se refiere a una entrevista con el expresidente Cárdenas que estaba "profundamente preocupado" por el hostigamiento de que era objeto el gobierno guatemalteco, y trataba de ayudar lo más que podía. Según la CiA, el autor del memorándum era Manuel Pinto Usaga, excónsul de Guatemala en México. Doc, 17, “From Árbenz personal effects”. NACP Md., CIA-RDP78-00915R00090003-5. José Steinsleger cuenta que en agosto de 1954 en un encuentro casual con el poeta Luis Cardoza y Aragón, Cárdenas le dijo “Nos traicionaron”. Lamentablemente no sabemos cómo ayudó Cárdenas y tampoco quién lo traicionó. José Steinsleger, "Diez años de primavera y 60 de invierno de involución”, La Jornada (18 jun. 2014). 
calles y publicaron manifiestos en los periódicos en defensa de Guatemala. No obstante, los ecos de estas movilizaciones no llegaron muy lejos porque, según el periódico francés $L e$ Monde, la prensa mexicana no los reportaba. ${ }^{92}$

La embajada de México en la ciudad de Guatemala llegó a albergar a 318 refugiados, incluido el presidente depuesto, su familia y algunos miembros de su gabinete. Su estancia se prolongó casi tres meses, más de lo habitual en esas circunstancias, porque la junta militar se negaba a emitir los salvoconductos. En esas semanas la sede de la representación mexicana fue objeto de manifestaciones hostiles por parte de grupos anticomunistas. Protestaban contra la protección de personajes a los que acusaban de genocidio y contra la supuesta parcialidad del embajador Primo Villa Michel, que no había abierto las puertas de la embajada a los anticomunistas que huían de la represión arbencista. Exigían que fuera declarado persona non-grata. ${ }^{93}$

La permanencia de Árbenz en la embajada era muy incómoda para el gobierno mexicano. Primeramente comprometía a Ruiz Cortines con un personaje que Estados Unidos consideraba su enemigo y, en segundo lugar, subía el tono de la discusión en México. Por último, la coyuntura económica era desfavorable a una disputa con Washington. Apenas

92 "Les événements du Guatemala ont provoqué des vives réactions dans les milieux universitaires du Mexique“, Le Monde (7 jul. 1954).

93 “600 damas guatemaltecas dirigen un mensaje cablegráfico al presidente Adolfo Ruiz Cortines. Piden el retiro de nuestro embajador Villa Michel”, El Informador (13 jul. 1954), año XXXVII, t. CXXXIX, núm. 12963; "Se ha pedido la destitución de Villa Michel", Excelsior (13 jul. 1954), Sección A, primera plana; "Piden el retiro de Villa Michel”, El Universal (13 jul. 1954), Sección Primera, p. 7. 
dos meses antes, el secretario de Hacienda, Antonio Carrillo Flores, había anunciado la devaluación del peso mexicano de 8.65 por dólar a 12.50 pesos.

Los principales periódicos de la Ciudad de México se quejaban de la presencia de Árbenz en la embajada; ponían en tela de juicio la tradición del asilo político, por ejemplo, el 5 de julio de 1954, el editorial de El Universal se titulaba "Refugiados y delincuentes". Denunciaba a los refugiados guatemaltecos de ser "extremistas políticos" que en su propio país habían cometido actos criminales. Advertía al gobierno que tratarían de propagar sus "ideas peligrosas" y provocarían el desorden. De paso se refería a los refugiados españoles como antecedente de los costos de la inmigración.

El 13 de julio, sin mayor trámite ni discusión, con base en la Doctrina Estrada, que reconoce el derecho de las naciones para mantener o sustituir sus gobiernos o autoridades, sin que sea necesario el reconocimiento explícito de naciones extranjeras para que esos gobiernos sean legítimos y, sin mayor discusión, el embajador Villa Michel presentó sus respetos al gobierno presidido por el jefe rebelde, Carlos Castillo Armas.

En el Informe del $1^{\circ}$ de septiembre de 1954 ante el Congreso, el presidente Ruiz Cortines reiteró la postura de su gobierno: México defendía la autodeterminación y los valores democráticos, pero condenaba el comunismo. "Durante nuestras discusiones en Caracas a propósito de la intervención del comunismo internacional en nuestras repúblicas, [expresamos] nuestro inequívoco rechazo a cualquier tipo de interferencia del comunismo internacional en nuestro 
hemisferio"; 94 nada dijo de la intervención de Estados Unidos. Respecto al hemisferio sólo declaró que la solidaridad continental era la mejor contribución que podía hacer a la paz universal. ${ }^{95}$

Unas semanas después, Jacobo Árbenz y su familia recibieron los salvoconductos que les permitieron viajar a México, donde permanecieron hasta el 17 de diciembre. En esa fecha viajaron a Europa con la intención de regresar al cabo de algunos meses pero, observaba la nota periodística, "para entonces se sabrá si nuestro gobierno lo permite". ${ }^{96}$

\section{Las secuelas del golpe en México}

La caída de Árbenz no liberó al gobierno mexicano de las presiones de Estados Unidos. Washington intentó impedir que el gobierno mexicano otorgara asilo político a Árbenz y a sus allegados. El 19 de agosto de 1954, el embajador Francis White entregó al subsecretario de Relaciones Exteriores, José Gorostiza, un memorándum informal que contenía las

94 Ruiz Cortines, “Discurso del 1ํ de septiembre de 1954, “, IV, p. 544. 95 Ruiz Cortines, "Discurso del 1을 de septiembre de 1954, “, IV, p. 544. 96 "Árbenz viaja a Europa”, El Informador (18 dic. 1954), año XXXVII, t. CXXXIX, núm. 13122, primera plana; "El expresidente de Guatemala, Coronel Jacobo Árbenz, salió anteayer a Suiza”, Excelsior (19 dic. 1954), Sección A, primera plana; “A Suiza se fue Jacobo Árbenz”, $E l$ Universal (19 dic. 1954), Sección Primera, p. 6. El expresidente Árbenz regresó a México en 1965, cuando, según su esposa, "disminuyeron las presiones”. La familia Árbenz fue prácticamente perseguida por la CIA donde quiera que iba. Al término de su primera estancia en México iniciaron un largo periplo que los llevó a Suiza, París, Praga, Moscú, Montevideo, La Habana. Jacobo Árbenz era un hombre destruido. Murió en la Ciudad de México en 1970, García Ferreira, "La cia y el exilio de Jacobo Árbenz”, pp. 59-82. 
sugerencias de su gobierno respecto a lo que había que hacer con los refugiados políticos guatemaltecos. El documento tiene seis puntos que pueden resumirse en uno: los comunistas tenían que irse de México. El gobierno podía entregarlos a Guatemala en calidad de delincuentes, puesto que allí ya habían sido enjuiciados y sentenciados por los crímenes que habían cometido, o enviarlos al país de su elección detrás de la cortina de hierro. ${ }^{97}$

Es muy probable que la propuesta haya sorprendido - $-y$ hasta escandalizado al funcionario mexicano. La SRE estaba - por tradición - comprometida con la defensa del asilo político. Esta era la posición de prominentes internacionalistas como Isidro Fabela y del mismo secretario Padilla Nervo. Además, los exiliados gozaban de la protección de la Sociedad de Amigos de Guatemala, a la que pertenecían distinguidos radicales y el expresidente Cárdenas. ${ }^{98}$

Ruiz Cortines se impacientaba. El 8 de octubre de 1954, el subsecretario Gorostiza recibió un Memorándum firmado

${ }^{97}$ Memorándum, Intervención del gobierno de E.U.A. en cuestión de los refugiados políticos de las misiones diplomáticas extranjeras en Guatemala", AGE, SRE, Correspondencia de la Embajada de E.U.A., f. 1-5 (19 de agosto de 1954). Este descabellado plan se iba a proponer a México y a la Unión Soviética con el fin de exhibir a los comunistas y de castigarlos; por ejemplo, preveía que perdieran la nacionalidad porque eran agentes de una potencia extranjera. WH/PW 211 "Quarter "I" no. DDP1-1798 (5 de agosto de 1954), NACP, Md.

${ }^{98}$ En una entrevista, el antiguo diplomático estadounidense, Spruille Braden, quien pasó a la historia por el conflicto con el presidente Perón en Argentina en 1945, afirmó que los exiliados guatemaltecos eran miembros del Partido Comunista, "fellow travellers y gangsters"; que en 1954 Cárdenas hospedaba en su "finca o lo que sea, en México". The Reminiscences of Spruille Braden, Oral History Research Office, Columbia University, 1959, 3029, tercera parte, vol. viII, Butler Library, 10 de noviembre de 2014. 
por Salvador Olmos, secretario particular del presidente, con el encabezado "Por instrucciones del Presidente de la República”. La primera línea de la Sección 1 advertía “Que es en el urgente interés del Estado mexicano y del pueblo mexicano, ahora más que nunca, extraditar al guatemalteco Rosenberg (que había sido jefe de policía del gobierno arbencista), cuya extradición ha sido solicitada con base en acusaciones criminales, y debe proceder de inmediato". ${ }^{99}$

El mencionado documento añadía que el gobierno no tenía que "exponerse él mismo a peligros internacionales por defender a una persona acusada de ser un criminal en otro país”. Le recordó a la SRE que la extradición es una prerrogativa presidencial, con la natural consecuencia de que nadie podía usurpar esa autoridad. El párrafo 10 del Memorándum señalaba los riesgos que acarreaba la negativa del gobierno mexicano a atender la solicitud de Estados Unidos, en primerísimo lugar la "súbita” aparición de "inquietud interna”:

Estados Unidos quiere que los gobiernos latinoamericanos den prueba con hechos indiscutibles, de que están contra el comunismo internacional que respalda la Unión Soviética. Si no es así, aparecerá súbitamente la inquietud interna, que no cesará hasta que el comunismo haya sido totalmente eliminado de las Américas, dado el hecho de que esta región pertenece de facto a la esfera de influencia política y económica de Estados Unidos. ${ }^{100}$

99 "Correspondencia entre la Secretaría de la Presidencia y la SRE sobre la solicitud de [...]”, AGE, SRE, exp. VII-97-1-2 y 3, ff. 6-20, 1954. La policía mexicana arrestó al Mayor Rosenberg (o Rosemberg) en octubre de 1954. "Reconocidos comunistas telefonearon a algunos diarios para denunciar el secuestro", El Informador (5 oct. 1954), año XXXVIII, t. CXL, núm. 10347, primera plana.

100 "Correspondencia entre la Secretaría de la presidencia y la SRE sobre 
Rara vez un presidente mexicano había expresado por escrito, de manera tan clara y directa, su percepción de la amenaza que Estados Unidos representaba para la estabilidad interna del país. El párrafo 6 de este memorándum advertía que Estados Unidos tenía un interés particular en imponer castigos a los comunistas por sus ofensas "a la libertad y a la democracia”, y argumentaba que la extradición del Mayor Rosenberg podía ser una prueba fehaciente de "naturaleza legal y anticomunista para salvar a México de las represalias y la desconfianza anticomunistas de Estados Unidos". ${ }^{101}$ Mientras Relaciones se sometía a la instrucción presidencial, el 22 de octubre fueron detenidos 13 líderes del PCM, entre ellos Valentín Campa y Dionisio Encinas, acusados de violar el reglamento de policía. La prensa hablaba de que se había conjurado un plan de agitación comunista. ${ }^{102}$

El apoyo de la Sociedad Amigos de Guatemala permitió a Rosemberg sostener una batalla legal que se prolongó hasta que recibió el estatus de refugiado político. Fue liberado en mayo de $1955 .{ }^{103}$ Es probable que para entonces disminuyeran las presiones de Washington.

la solicitud de...” AGE, SRE, exp. VII-97-1-2 y 3, ff. 6-20, 1954.

101 "Correspondencia entre la Secretaría de la Presidencia y la SRE". AGE, SRE, exp. VII-97-1-2 y 3, ff. 6-20, 1954.

102 "13 líderes comunistas detenidos: Valentín Campa y Dionisio Encinas”, El Informador (23 oct. 1954), año XXXVIII, t. CXL, núm. 13065, primera plana.

103 El presidente Castillo Armas insistía en su extradición. Estaba acusado de "asesino de masas” y de otras “atrocidades” contra los anticomunistas guatemaltecos. En la cárcel, Rosenberg inició un largo proceso para definir su estatus legal en México. Su defensa estuvo a cargo de Carmen Otero y Gama, cuñada de Lombardo Toledano. Según la sRE, Rosemberg no se había asilado en la embajada en Guatemala “Tampoco había ingresado al país conforme a canales diplomáticos aceptados”. La conclusión 


\section{México y la lección guatemalteca}

La intervención en Guatemala fue una advertencia y un recordatorio de Estados Unidos a los latinoamericanos de que su bienestar dependía de una relación armoniosa con Washington. ${ }^{104}$

El presidente Ruiz Cortines parece haber registrado el mensaje. En agosto de 1955 y en respuesta a una solicitud directa de Eisenhower de información a propósito de la situación en México, el embajador White, reportaba que su relación con el presidente mexicano había mejorado notablemente después de los acontecimientos en Guatemala. ${ }^{105}$ Atribuía el cambio de tono a la poderosa reacción de los "elementos estables" de la sociedad mexicana - banqueros, cámaras de industria y comercio, capitalistas y clases medias en ascenso - contra la devaluación del peso mexicano, pero, sobre todo, contra el apoyo al gobierno de Árbenz. Desde su perspectiva, la oposición conservadora había sido más eficaz que la presión de la izquierda. ${ }^{106}$

del secretario Padilla Nervo era que no podía ejercer el derecho de asilo en este caso. "Mexico may turn down Guatemalan chief for asylum", The Paris News (10 oct. 1954), p. 28. "Mexico orders arrest. May deport former Secret Police head of Guatemala", The New York Times (4 dic. 1954). Ese mismo mes, el secretario de Gobernación solicitó la liberación del mayor Rosenberg, que había aportado pruebas de su condición de asilado político. El 24 de mayo de 1955, Rosenberg fue liberado. "Two Guatemalans freed", The New York Times (25 mayo 1955).

104 Al menos éste fue el mensaje del secretario de Estado, John Foster Dulles en la X Conferencia Interamericana, celebrada en Caracas en abril de 1954. Rabe, Eisenhower and Latin America, pp. 50-53.

105 "Letter from the Ambassador in Mexico (White) to the President", 29 de agosto de 1955, FRUS, The Americas 1955-1957, vol. vi, p. 680. 106 "La oposición mexicana estaba dividida, pero [los costos] de incurrir 
El embajador relataba que en junio de 1954 recibió una primera invitación del presidente Ruiz Cortines para que lo visitara en su residencia. A partir de entonces los encuentros fueron casi semanales. White se ufanaba de haber convencido a su anfitrión de que el gobierno guatemalteco realmente era una amenaza para México, y de la importancia de una colaboración más estrecha con Estados Unidos para combatir el comunismo. ${ }^{107}$ Ruiz Cortines sólo le pidió discreción, porque la opinión pública mexicana, le dijo, era muy suspicaz, y miraba con desconfianza a todo gobierno que colaborara con ellos, especialmente en materia de seguridad. ${ }^{108}$ El testimonio más importante de esta cooperación fue la decisión del presidente Ruiz Cortines de extraditar a por lo menos 30 guatemaltecos para que fueran juzgados en su país. Poco se supo de esto en México. ${ }^{109}$

Contrariamente a lo que temían algunos, la oposición pública del gobierno a la política de Estados Unidos en Guatemala no alteró la armonía en las relaciones entre los dos gobiernos. El 1ำ de septiembre de 1954, The New York Times, reportaba que su cordialidad había sido confirmada por la decisión del presidente Eisenhower de suspender las

en la ira de los poderosos anticomunistas eran superiores a los costos de desilusionar a la izquierda". Buchenau, "Por una Guerra Fría más templada”, p. 133.

107 "Letter from the Ambassador in Mexico (White) to the President", FRUS, The Americas 1955-1957, vol. vi, p. 680.

108 "Letter from the Ambassador in Mexico (White) to the President", FRUS, The Americas 1955-1957, vol. vI, p. 680.

109 Nancy Robinson, "México frente a la crisis de Guatemala en 1954", [en línea] http//www. raco.cat/index.php/boletinamericanista/article/ viewFile/98476/146.119”, p. 231. 
tarifas a las importaciones mexicanas de plomo y zinc que el Congreso había votado.

La cooperación del presidente Ruiz Cortines con la política anticomunista de Washington obliga a revisar la idea de la relación especial entre Estados Unidos y México. En este caso al menos, la postura de Washington frente a la política exterior mexicana no era muy distinta a la que mantenía frente a los demás países de la región. Además, su confianza en la capacidad del PRI de mantener el orden interno no era ilimitada. En diferentes ocasiones Eisenhower hizo referencia a la fragilidad de "la estabilidad interna" mexicana. Tampoco creía que México fuera inmune al contagio comunista. Por ejemplo, en 1953, con base en un argumento político bloqueó un voto del Congreso para imponer tarifas a la importación de plomo y de zinc: "Si construimos barreras tan altas al comercio con México, creo que aumentaría rápidamente la posibilidad de que se vuelva comunista”. ${ }^{110}$ En 1960 expresó su temor de que los mexicanos renunciaran a la alianza con Estados Unidos, ante la creciente influencia de la revolución cubana y su descontento con las tácticas de Washington contra el régimen de Fidel Castro "y si los comunistas llegan al poder allí [en México] entonces tendríamos que irnos a la guerra”. ${ }^{111}$

A partir de 1955 la atención de Ruiz Cortines estuvo en otros asuntos. Ese año habría elecciones para la renovación de la Cámara de Diputados y de varias gubernaturas, una situación siempre delicada para los gobiernos del PRI. Las diferencias políticas entre los mexicanos no habían

110 Citado en Rabe, Eisenhower and Latin America, p. 70.

111 RABE, Eisenhower and Latin America, p. 165. 
desaparecido y los síntomas de inquietud y descontento en el movimiento sindical, en el campo y entre los estudiantes universitarios, se multiplicaron. En la segunda mitad del sexenio 1955-1958, el número de huelgas aumentó de 135 registradas a 740 en 1958, involucró a más de 60500 huelguistas. Rubén Jaramillo, el líder agrario del estado de Morelos, exigía tierras al frente de un grupo armado. La respuesta del presidente fue "mantener la paz a cualquier precio, desde el campo y los pueblos hasta las grandes ciudades". ${ }^{112}$

Ruiz Cortines también recurrió a instrumentos políticos, por ejemplo, el fortalecimiento del PRI. En 1953 se reconoció el derecho al voto de las mujeres. El partido llevó a cabo una amplia campaña de afiliación que engrosó sus filas con 3000000 más de miembros. En las elecciones de 1955, el PRI obtuvo $90 \%$ del voto, que en números absolutos ascendía a más de 5.5 millones de votos, como si hubiera captado la totalidad de nuevas votantes, pues en 1952 había obtenido 2.7 millones de votos.

Entre el 26 y el 28 de marzo de 1956, en el curso de un encuentro trilateral de América del Norte, ${ }^{113}$ Ruiz Cortines tuvo una entrevista privada con Eisenhower, quien subrayó que el pueblo estadounidense estaba "muy preocupado por la subversión y la penetración comunista en los gobiernos [latinoamericanos]". Aunque no llegó a sugerir abiertamente que México rompiera relaciones con la Unión Soviética,

112 Ruiz Cortines, “Discurso”.

113 Esta reunión fue propuesta por el Assistant Secretary Holland con la intención de crear un consejo trilateral. Contra la mejor opinión de los embajadores en Canadá y México, la reunión se llevó a cabo con la participación de los presidentes Eisenhower y Ruiz Cortines, y del primer ministro canadiense, Louis St. Laurent. 
apuntaló su advertencia con un mensaje cifrado: las embajadas de ese país eran "centros de espionaje, de sabotaje y de actividades subversivas". ${ }^{114}$ Una vez que el presidente mexicano confirmó su compromiso con el combate anticomunista, pasaron a discutir temas de índole comercial y de cooperación bilateral. ${ }^{115}$

El 29 de noviembre de 1957, el presidente Ruiz Cortines recibió al nuevo embajador de Estados Unidos, Robert C. Hill, menos de dos semanas después de la nominación de Adolfo López Mateos como candidato del PRI a la presidencia de la República. Después de pedirle que mantuviera sus conversaciones confidenciales, le agradeció el respeto que mostraba a la política interna en un momento tan importante. Luego habló de López Mateos, a quien - dijo-, él había guiado en su camino hacia la candidatura. "Es exactamente igual a mí”. ${ }^{116}$ Sobre todo, aseguró el presidente al

114 En 1956 sólo Argentina, México y Uruguay tenían relaciones diplomáticas con la Unión Soviética. Según un documento de la embajada de Estados Unidos en México, la representación soviética era “desproporcionada” a la relación soviético mexicana que era muy limitada, y concentrada en al área cultural. Según este reporte, la mayoría de los funcionarios de la embajada provenían del medio militar. La embajada incluía “grandes unidades” de propaganda. Tenía además el apoyo de las embajadas de Checoslovaquia y de Polonia, también muy activas. Raymond G. Leddy to Kennedy M. Crockett, Esq. Officer in charge of Mexican Affairs, DoS (24 de septiembre de 1957), 611.12/9-2457 NACP, Md.

115 "Memorandum of conversation" (27 de marzo de 1956), Participants: The President, President Ruiz Cortines of Mexico. L.t. Colonel Vernon A. Walters, FRUS, 1955-1957, vol. vi.

116 From ARA Mr. R. R. Rubottom to the Secretary, "Comments on U.S.-Mexican Relations made by the President of Mexico”, ARA, 611.12/12-2357, NACP, Md. 
embajador, "sabe cómo tratar a los comunistas", "como yo", dijo sibilino. ${ }^{117}$

\section{EPÍLOGO}

Al aproximarse la fecha de la sucesión presidencial de 1958, la inquietud y el creciente nerviosismo que se manifestaba en la sociedad fueron un poderoso argumento para que Ruiz Cortines centralizara todavía más la decisión en torno a su sucesor, al que designó personalmente sin previa negociación ni consulta. Adolfo López Mateos (1958-1964) fue postulado candidato del PRI, y en un despliegue de unidad del "sector revolucionario” por dos de los tres partidos de oposición registrados, el Partido Popular Socialista (PPS) de Lombardo, y el Partido Auténtico de la Revolución Mexicana (PARM), que se había fundado para canalizar la participación electoral de los oficiales del ejército en retiro. López Mateos contendió sólo contra el candidato del PAN, Luis H. Álvarez.

La elección de 1958 fue la primera en la que la elite política no se dividió, como ocurrió en 1940, en 1946 y en 1952. Sin embargo, la unidad no se había restablecido, como pudo comprobarlo López Mateos, una vez en la presidencia donde él mismo tuvo que enfrentar las perturbaciones que provocaba la fractura en el seno de la elite política. La concentración de la lucha electoral en dos polos no reflejaba una verdadera reorganización de las fuerzas políticas, sino que fue una muestra de la debilidad de la representación

117 From ARA-Mr. R. R. Rubottom to the Secretary, "Comments on U.S.-Mexican Relations made by the President of Mexico", ARA, 611.12/12-2357, NACP, Md. 
institucional del conflicto que se desplazó a otros terrenos del sistema político, ${ }^{118}$ pero dejó al descubierto la fuerza del cardenismo donde se hunden las raíces de la fractura política más significativa del siglo xx mexicano.

El episodio guatemalteco muestra el pragmatismo esencial del presidente Ruiz Cortines, que logró mantener la política interna mexicana fuera del alcance de Washington: para ello recurrió a cuanto recurso tuvo a la mano. El cambio de actitud frente al embajador White después del golpe en Guatemala, indica un nuevo cálculo de los riesgos que acarreaba la desconfianza de los estadounidenses. Sus pláticas semanales pueden ser vistas como subordinación. Sin embargo, habrá que reconocer que a cambio, Ruiz Cortines puso a salvo un espacio aunque estrechísimo en el que sólo actuaban los mexicanos: la sucesión presidencial. Repudió el comunismo cuanto fue necesario, para esquivar el intervencionismo estadounidense en la política interna mexicana. Si comparamos esta situación con la de otros países latinoamericanos, todo sugiere que al hacerlo evadió una causa de inestabilidad.

Por último, este episodio invita a una reflexión más general. La estrategia de Estados Unidos contra la presunta expansión del comunismo provocaba exactamente lo que quería evitar, porque desestabilizaba el status quo regional y el equilibrio interno de los países en los que intervenía. Las repercusiones de esta estrategia eran más perturbadoras que el impacto de las políticas que trataba de frenar. La batalla contra el comunismo desestabilizaba los equilibrios internos

118 Véase Loaeza, Clases medias y política en México. 
de estos países, es decir, acarreaba las consecuencias que la ofensiva anticomunista de Estados Unidos quería evitar.

El episodio guatemalteco y su impacto en México revelan la conexión entre la continuidad de los equilibrios políticos internos y el orden regional. Un orden regional estable, como el que prevalecía en América Latina en 1954, no estaba necesariamente amenazado por reformas en el ámbito local, o bien, éstas no podían ir muy lejos. Sin embargo, en un contexto regional frágil o inestable, la transformación del orden interno agrava esa fragilidad y desestabiliza prácticamente a todos los países de la región, como ocurrió con la revolución cubana en 1959. La intervención estadounidense en Guatemala cimbró el orden hemisférico. La susceptibilidad de todos los países de la región al triunfo de los revolucionarios cubanos sugiere que el golpe contra Árbenz tuvo un efecto corrosivo de mediano plazo que escapó al ojo vigilante de Washington. Por consiguiente, puede pensarse que esta operación preparó el terreno para que después los acontecimientos cubanos repercutieran en todos los países de la región y alteraran definitivamente el orden hemisférico.

\section{SIGLAS Y REFERENCIAS}

AGN Archivo General de la Nación, Ciudad de México, México.

AGN, $P$, MAV Archivo General de la Nación, fondo Presidentes, Miguel Alemán Valdés, Ciudad de México, México.

AGE, SRE Archivo Genaro Estrada, Secretaría de Relaciones Exteriores, Ciudad de México, México.

AMGM, ITAM Archivo Manuel Gómez Morín, Instituto Tecnológico Autónomo de México, Ciudad de México, México.

ARA Bureau of Interamerican Affairs, E. U.

FRUS Foreign Relations of the United States, E. U. 
NACP National Archives and Records Administrattion, College Park, Md., E. U.

Brandengurg, Frank

The Making of Modern Mexico, New Haven, Prentice Hall, 1964.

Buchenau, Jürgen

"Por una Guerra Fría más templada: México entre el cambio revolucionario y la reacción estadounidense en Guatemala y Cuba”, en Spenser (coord.), 2004, pp. 119-171.

CÁrdenas, Héctor

Historia de las relaciones entre México y Rusia, México, Secretaría de Relaciones Exteriores, Fondo de Cultura Económica, 1993.

CÁrdenas, Lázaro

Obras I, vol. 2, Apuntes 1941-1956, México, Universidad Nacional Autónoma de México, Nueva Biblioteca Mexicana, 1973.

Obras I, vol. 3, Apuntes 1957-1966, México, Universidad Nacional Autónoma de México, Nueva Biblioteca Mexicana, 1973.

Cardoza y Aragón, Luis

La revolución guatemalteca, Montevideo, Ediciones Pueblos Unidos, 1956.

Casasola Zapata, Gustavo

Historia Gráfica de la Revolución Mexicana, 1900-1970, México, Trillas, vol. 8.

Castañeda, Jorge

México y el orden internacional, México, El Colegio de México, 1956. 
Connell-Smith, Gordon

The Inter-American System, Londres, Oxford University Press, 1966.

Cooney, John

The American Pope. The Life and Times of Francis Cardinal Spellman, Nueva York, New York Times Books, 1984.

Cosío Villegas, Daniel

Ensayos y Notas, México, Editorial Hermes, 1966.

Memorias, México, Joaquín Mortiz, Secretaría de Educación Pública, 1986.

“México y Estados Unidos”, en Cosío Villegas, 1966.

Covarrubias, Ana

"México y la Revolución Cubana. La independencia de un país dependiente”, en Sotomayor y Vega (coords.), 2008, pp. 25-46.

Craig, Campbell y Frederik Logevall

America's Cold War, The Politics of Insecurity, Cambridge, Mass., The Belknap Press of Harvard University Press, 2012.

FeIN, Seth

"Producing the Cold War in Mexico. The public limits of convert communications", en JosePH y SPENSER (eds.), 2012.

Fenn, Peggy

"México, la No-Intervención y la autodeterminación en el caso de Cuba”, Foro Internacional, Iv: 1 (13) (jul.-sep. 1963), pp. 1-19.

FOWLER, Will (coord.)

Gobernantes mexicanos, México, Fondo de Cultura Económica, 2008. 
García Ferreira, Roberto

“La Cia y el exilio de Jacobo Árbenz”, en Perfiles Latinoamericanos, 28 (2006), pp. 59-82.

"El caso de Guatemala: Arévalo, Árbenz y la izquierda uruguaya, 1950-1971”, en Mesoamérica, 49 (2007), pp. 25-58.

Garciadiego, Javier y Emilio Kourí (comps.)

Revolución y exilio en la historia de México. Del amor de un historiador a su patria adoptiva. Homenaje a Friedrich Katz, México, El Colegio de México, University of Chicago, Era, 2010.

Gillingham, Paul y Benjamin T. Smith (eds.)

Dictablanda: politics, work and culture in Mexico, 1938-1968, Durham, Duke University Press, 2014.

Gleijeses, Piero

Hope shattered. The Guatemalan Revolution and the United States, 1944-1954, Princeton, New Jersey, Princeton University Press, 1992.

Hove, Mark

"The Árbenz factor: Salvador Allende, U. S.-Chilean relations and the 1954 U. S. intervention in Guatemala", en Diplomatic History, 31: 4 (2007), pp. 623-663.

Huntington, Samuel

Political order in changing societies, New Haven, Conn., Yale University Press, 1969.

JÉIFETs, Víctor y Lázar JÉifets

"Los archivos rusos revelan secretos: el movimiento de la izquierda latinoamericana a la luz de los documentos de la Internacional Comunista", en Anuario Americanista Europeo, 8 (2010), 2221-3872, Sección Documentación, pp. 35-64. 
Joseph, Gilbert y Daniela Spenser (eds.)

In from the Cold: Latin America's new Encounter with the Cold War, Durham, Duke University Press, 2012.

KaTZ, Friedrich

The Secret War in Mexico. Europe, the United States and the Mexican Revolution, Chicago, Universidad de Chicago, 1981.

Keller, Renata

“A foreign policy for domestic consumption. Mexico's lukewarm defense of Castro, 1959-1969", en Latin American Research Review, 2 (2012), pp. 100-119.

KNight, Alan

“Cardenismo: Juggernaut or jalopy?”, en Journal of Latin American Studies, 1 (1994), pp. 73-107.

Leffler, Melvyn

"The American conception of national security and the beginnings of the Cold War, 1945-1948", en The American Historical Review, 2 (1984), pp. 346-381.

LiNZ, Juan

“Teoría del régimen autoritario: el caso de España”, en PAYne (comp.), 1978, pp. 205-263.

LOAEZA, Soledad

Clases medias y politica en México. La querella escolar 19591963, México, El Colegio de México, 1988.

El Partido Acción Nacional, la larga marcha. Oposición leal o partido de protesta, México, Fondo de Cultura Económica, 1999.

"Mexico in the fifties: Women and Church in Holy Alliance", en Women's Studies Quarterly, 33: 3-4 (otoño-invierno 2005), pp. 138-160.

La restauración de la Iglesia católica en la transición mexicana, México, El Colegio de México, 2012. 
“La reforma política de Manuel Ávila Camacho”, en Historia Mexicana, LXIII:1 (249) (jul.-seo. 2013), pp. 251-358.

Meyer, Lorenzo

México y el mundo: historia de sus relaciones exteriores, t. 6 . La marca del nacionalismo, México, Colegio de México, 2010.

Morgenfeld, Leandro Ariel

"El inicio de la Guerra Fría y el sistema interamericano. Argentina frente a Estados Unidos en la Conferencia de Caracas (1954)", en Contemporánea, Historia y Problemas del siglo XX, 1 (2010), pp. 75-97.

Novo, Salvador

La vida en México en el periodo presidencial de Adolfo Ruiz Cortines, México, Conaculta, 1996.

Ojeda, Mario

Alcances y límites de la política exterior de México, México, El Colegio de México, 1976.

Patch, Chester y Elmo Richardson

The Presidency of Dwight D. Eisenhower, Kansas, University Press of Kansas, 1991.

Paxman, Andrew

"Cooling to cinema and warming to television: State mass media policy, 1940-1964”, en Gillingham у Sмitн (eds.), 2014.

Payne, Stanley G. (comp.)

Política y sociedad en la España del siglo XX, Madrid, Akal editores, 1978.

Pellicer, Olga

"La revolución cubana en México", en Foro Internacional, vIII: 4 (32) (abr. 1968), pp. 360-383.

"México en la oEA", en Foro Internacional, vi: 2/3 (22-23) (oct. 1965), pp. 288-302. 
México y la revolución cubana, México, El Colegio de México, 1972.

Rabe, Stephen

Eisenhower and Latin America. The Foreign Policy of Anticommunism, Chapel Hill, The University of North Carolina Press, 1988.

The Killing Zone. The United States wages Cold War in Latin America, Oxford, Oxford University Press, 2012.

Robinson, Nancy

“México frente a la crisis de Guatemala en 1954" [en línea] http//www.raco.cat/index.php/bolelunamericancanista/article/view tile/98476/146.119.

Rodríguez Kuri, Ariel

"Los años maravillosos: Adolfo Ruiz Cortines”, en Fow LER (coord.), 2008, pp. 263-286.

Ruiz Cortines, Adolfo

“Discurso del 1o de septiembre de 1954", en Cámara de Diputados, Xlit Legislatura, Los presidentes de México ante la nación, 1821-1966, México, Talleres Gráficos de la Nación, vol. Iv.

Sabino, Carlos

La bistoria silenciada. 1944-1989, I, Revolución y Liberación, México, Fondo de Cultura Económica, 2007.

SERvín, Elisa

"Propaganda y Guerra Fría: la campaña anticomunista en la prensa mexicana del medio siglo", en Signos Históricos, 11 (2004), pp. 8-39.

SEWeLl, Bevan

"A perfect (Free-Market) world? Economics, the Eisenhower administration, and the Soviet economic offensive in Latin America", en Diplomatic History, 32 (2008), pp. 841-848. 
Serra Puche, Mari Carmen, José Francisco Mejía Flores y Carlos Sola Ayape (eds.)

1945, entre la euforia y la esperanza: el México posrevolucionario y el exilio republicano español, México, Fondo de Cultura Económica, 2014.

Smith, Gaddis

The Last Years of the Monroe Doctrine, 1945-1993, Nueva York, Hill y Wang, 1994.

Sola Ayape, Carlos

"Contra las cortes de ultratumba' y la 'legalidad de opereta': escritores de la derecha mexicana y sus críticas al exilio republicano español”, en Serra, Mejía y Sola Ayape (eds.), 2014.

Sotomayor Velázquez, Arturo C. y Gustavo Vega Cánovas (coords.)

El mundo desde México. Ensayos de política internacional. Homenaje a Olga Pellicer, México, El Colegio de México, Instituto Tecnológico Autónomo de México, Centro de Investigación y Docencia Económicas, 2008.

Spenser, Daniela

The Impossible Triangle. Mexico, Soviet Russia, and the United States in the 1920's, Durham, Duke University Press, 1999. "Vicente Lombardo Toledano envuelto en antagonismos internacionales”, en Garcíadiego y Kourí (comps.), 2010.

Spenser, Daniela (coord.)

Espejos de la Guerra Fría: México, América Latina y el Caribe, México, Secretaría de Relaciones Exteriores, Centro de Investigaciones y Estudios Superiores en Antropología Social, 2004.

Torres, Blanca

México y el mundo. Historia de sus relaciones exteriores, t. 7, De la guerra al mundo bipolar, México, El Colegio de México, 2010. 